DOI https://doi.org/10.30525/978-9934-588-47-1.8

\title{
ФОРМИРОВАНИЕ КОМПОЗИЦИОННЫХ МАТЕРИАЛОВ ПРИ ИЗГОТОВЛЕНИИ ВОДОРАЗРУШАЕМЫХ ФОРМООБРАЗУЮЩИХ ЭЛЕМЕНТОВ
}

Кудрявцев П. Г.

\section{ВВЕДЕНИЕ}

В настоящее время в различных отраслях народного хозяйства широкое применение нашли водоразрушаемые формообразующие элементы, используемые при намотке изделий из полимерных композиционных материалов, при литье металлов и пластмасс. Под термином «композиционный материал» обычно понимают структурно-неоднородные системы, полученные в результате смешения нескольких разнородных компонентов и обладающие свойствами, отсутствующими у исходных материалов. В соответствии с этим определением, к композитам можно отнести все гетерогенные системы, представляющие собой сочетания двух и более химических веществ или различных фаз, при этом между фазами в композиционном материале должны наблюдаться четко обозначенные границы раздела. К таким материалам относятся и водоразрушаемые формообразующие элементы. Основное применение эти материалы нашли при изготовлении ракетных двигателей на твердом топливе.

Ракетные двигатели на твердом топливе (РДТТ) являются одним из наиболее важных типов ракетных двигателей, имеющих широкое практическое применение. Они используются в ракетной, ракетнокосмической и авиационной технике. Жидкостные баллистические ракеты как в США, так и в России вытесняются твердотопливными ракетами, и в настоящее время они полностью заменили ракеты с ЖРД, занимая теперь монопольное положение в этом классе вооружения ${ }^{1}$.

РДТТ используют в летательных аппаратах многих типов: баллистических ракетах, космических системах и ракетах-

${ }^{1}$ Лавров Л.Н., Думин О.С., Соколовский М.И. и др. Конструкции ракетных двигателей на твердом топливе / Под общ. ред. чл. корр. РАН, д.т.н., проф. Л.Н. Лаврова Москва : Машиностроение, 1993. 215 с. 
носителях, крылатых ракетах и самолетах, зенитных и авиационных ракетных комплексах. РДТТ используются как в качестве основных маршевых двигателей ракет, так и в качестве вспомогательных двигателей для управления различными летательными аппаратами, отделения ракетных ступеней и отдельных блоков, для торможения и мягкой посадки, аварийного спасения космических кораблей и индивидуальных капсул пилотов.

Основным конструктивным элементом РДТТ является корпус двигателя. Корпуса РДТТ могут иметь различную форму: цилиндрическую, коническую, сферическую, овалоидную или тороидную. Возможны и комбинированные формы корпуса. Корпус может быть цельным или разъемным, разделенным на секции, имеющие отъемные днища. В качестве современных материалов корпуса применяют стеклопластики, органопластики, углепластики. В ряде случаев используются комбинации различных материалов.

Силовая оболочка корпуса в виде кокона может иметь форму овалоида вращения, шара, оболочки с цилиндрической (конической) частью и днищами различной формы. Диаметр переднего полюсного отверстия оболочки корпуса в виде кокона определяют исходя из необходимости размещения узлов воспламенителя, аварийного выключения, телеметрии и так далее. Диаметр заднего полюсного отверстия определяется условиями компоновки соплового блока и корпуса. Кроме того, эти отверстия являются технологическими элементами при изготовлении корпусов методом намотки.

Развитие этой области техники связано с разработкой и широким внедрением новых конструкционных материалов, среди них важное место занимают волокнистые композиционные материалы. Непрерывная силовая намотка - один из наиболее распространенных и высокоэффективных методов создания композиционных оболочек вращения. Технологической оснасткой при их изготовлении методом намотки являются формообразующие конструкции или оправки. При этом лента, образованная системой нитей, пропитывается полимерным связующим и с заданным первоначальным натяжением укладывается на оправку. Уникальные свойства неметаллических композиционных материалов позволяют не только существенно повысить качество конструкции РДТТ, уменьшить пассивную массу, но и уменьшить стоимость и трудоемкость изготовления.

Конструкции корпусов типа кокона образуются в процессе их намотки из композиционных материалов. Варьируя соотношением кольцевых и спиральных слоев, усиливая (армируя) тканями, 
металлической фольгой, специально намотанными салфетками, изменяя ширину ленты, угол намотки, натяжение ленты, степень армирования (рисунок намотки, крепления слоев), можно варьировать требуемые свойства конструкции в широком диапазоне. При создании таких корпусов необходимо учитывать зависимость характеристик композиционного материала от физикомеханических свойств теплозащитного и герметизирующего покрытий внутренней поверхности корпуса, конструкции и материала оправки (оснастки) для изготовления корпуса.

При проектировании корпуса следует учитывать усадочные характеристики материала силовой оболочки, технологической оснастки и теплозащитных покрытий. Такие воздействия происходят как в процессе намотки, в процессе отверждения материала корпуса двигателя, так и в процессе изготовлении заряда. Эти воздействия имеют достаточно большую длительность (до 30 суток), тепловое $\left(50-70^{\circ} \mathrm{C}\right)$ и силовое $(2,0-3,0$ МПа) воздействие, и при изготовлении двигателя происходит усадка используемых материалов ${ }^{2}$.

Силовая оболочка простейших корпусов типа кокона (Рисунок 1) является несущим элементом конструкции и представляет собой тело вращения (с днищами и цилиндрической частью). Она изготавливается методом намотки армирующего материала на специально подготовленную оправку. Для намотки используются нити, жгуты или ленты, пропитанные связующим компонентом. Полученная таким образом конструкция подвергается дальнейшей термообработке для отверждения и упрочнения связующего компонента.

2 Соколовский М.И. Развитие конструктивно-компоновочных схем крупногабаритных ракетных двигателей твердого топлива. Известия Российской Академии наук. Энергетика. № 2, 2003, с. 97; Фахрутдинов И.Х., Котельников А.В. Конструкция и проектирование ракетных двигателей твердого топлива. Москва : Машиностроение, 1987; Суходоева А.А. Численный анализ напряженно-деформированного состояния и оценка прочности оправок для намотки композиционных оболочек. Пермь : ПГТУ, 2000. 

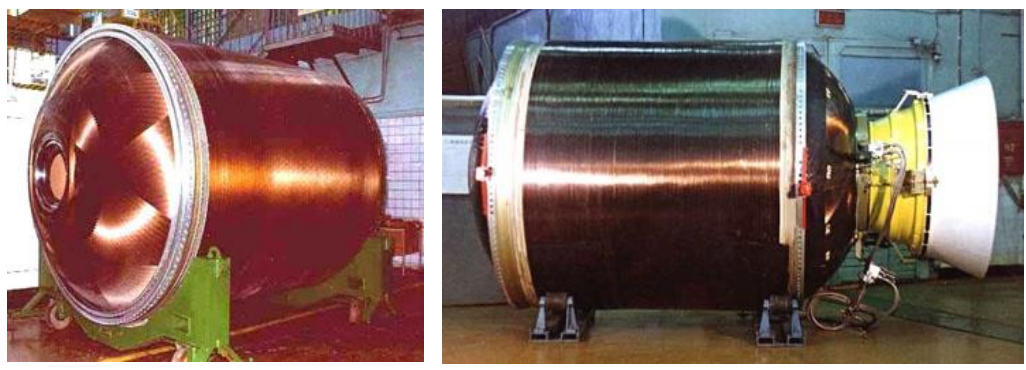

Рисунок 1. Цельномотанный органопластиковый корпус типа «кокон» маршевого двигателя РДТТ 15 Д291 третьей ступени ракет 15 Ж0 и $15 \% 961$ разработки и производства НПО «Искра», Пермь

Силовая оболочка корпусов типа кокона формируется спиральной намоткой, цилиндрическая часть ее усиливается тангенциальными слоями намотки. В полярных отверстиях силовой оболочки за счет адгезионных соединений крепятся закладные фланцы.

С учетом сказанного выше важной проблемой при изготовлении изделий типа кокона является конструкция и материал оправки. Для обеспечения технологичности конструкций, изготавливаемых из стеклопластиков, органопластиков или углепластиков методом намотки, обычно используются многоразовые оправки, изготовленные из металлов и пластмасс. Однако использование таких оправок для изготовления цельномотанных изделий весьма затруднено по конструкционным соображениям. Поэтому такие оправки обычно используются для изготовления отдельных элементов кокона, таких как цилиндрический корпус и закругленные крышки. Такой подход чаще используется при изготовлении не очень ответственного емкостного оборудования, используемого в гражданских целях. Для РДТТ секционный подход используется редко, так как наличие стыковочных швов приводит к резкому снижению прочности всей конструкции, а использование металлических фланцев приводит к увеличению коэффициента массового совершенства - отношения массы конструкции к массе заряда твердого топлива. Например, для крупногабаритных РДТТ уровень массового совершенства для верхних ступеней ракет составляет не более 0,08 . 
Оправка, в свою очередь, должна обеспечивать заданную форму и размеры изготавливаемой конструкции в условиях контактного давления со стороны формирующейся оболочки. Оправка должна иметь следующие свойства:

- иметь простую форму;

-иметь минимальное число разъемов, накладных или дополнительных вкладышей;

- также позволять снимать отвержденную деталь;

- обеспечивать осесимметричную форму детали без резких перепадов по толщинам.

Эти параметры обеспечивают равномерную усадку и устраняют деформацию готового продукта.

Конструкция корпуса РДТТ с его элементами должна позволять применение таких оправок, на которых разгрузочные манжеты зарядов (законцовки, уменьшающие концентрации напряжений по концам твердотопливного заряда) и внутренние теплозащитное покрытие могут изготавливаться в едином технологическом процессе изготовления корпуса РДТТ, то есть не требуют отдельной приклейки перечисленных элементов на готовый корпус.

При этом следует всегда учитывать, что в отличие от металлических конструкций, где обнаруженные после изготовления дефекты (например, в сварных швах) могут устраняться, качество готового стеклопластикового корпуса изменить уже нельзя. Это предъявляет исключительные требования к намоточным технологическим процессам, применяемому оборудованию, оснастке технологического процесса. При создании материала для оправки следует учитывать усадочные характеристики материала силовой оболочки и теплозащитных покрытий.

Такие требования могут быть обеспечены только оправками, изготавливаемыми из композиционных материалов. При этом они должны обладать уникальным объединенным комплексом химических и физико-механических свойств, таких как высокая прочность, высокая упругость, малый коэффициент термического расширения и одновременно легкая растворимость в воде. Это свойство особенно важно для удаления оправки из готового корпуса типа «кокон», после проведения всех технологических процессов. Перспективным направлением по созданию материалов для изготовления оправок является разработка водоразрушаемых 
материалов, обладающих высокой прочностью и способных легко и быстро разрушаться под действием воды.

Наибольшее развитие на российских предприятиях ракетнокосмической отрасли получили оправки на основе композиционного материала из кварцевого песка и связующего поливинилового спирта. Поливиниловый спирт (ПВС), полученный из поливинилацетата, является тактическим полимером. Кристалличность ПВС обусловлена наличием большого числа гидроксильных групп в полимере. На кристалличность полимера также оказывают влияние предыстория получения полимера, разветвленность, степень гидролиза и тип распределения остаточных ацетатных групп. Чем выше степень гидролиза, тем выше кристалличность образца ПВС. При термической обработке полностью омыленного продукта его кристалличность повышается и приводит к снижению его растворимости в воде. Чем выше число остаточных ацетатных групп в ПВС, тем меньше образование кристаллических зон. Исключением для растворимости является аморфный ПВС. Ввиду малой исходной кристалличности полимер (независимо от молекулярной массы) хорошо растворяется в воде ${ }^{3}$.

Однако их существенным недостатком являлось то, что после термического воздействия во время технологического процесса изготовления корпуса РДТТ происходила частичная деструкция поливинилового спирта, результатом которой являлось значительное снижение его растворимости в воде. При этом почти не удалось повысить скорость растворения за счет повышения температуры, а обработка еe с помощью струи перегретого водяного пара также не давала большого эффекта. Иногда процесс размывания оправки затягивался почти на неделю.

Решить эту проблему удалось двумя способами. Одним из способов явилось создание композиционных материалов на основе жидкого стекла, отверждаемого при нормальных условиях за счет удаления влаги. Второй способ основан на использовании растворимых в воде химических соединений для создания такого композита.

К материалам для изготовления водоразрушаемых формообразующих элементов предъявляются следующие основные требования: высокая прочность при повышенных температурах

${ }^{3}$ Бойко В.В. Синтез поливинилового спирта в водно-спиртовых средах : дис. канд. хим. наук. 02.00 .06 : Москва, 2004, 112 с. 
эксплуатации (до $200^{\circ} \mathrm{C}$ и выше), хорошая размываемость водой или водными растворами поверхностно-активных веществ, технологичность изготовления элементов, не дефицитность и не токсичность компонентов. Решающее влияние на качество намотанного изделия и на коэффициент реализации прочностных свойств полимерных композиционных материалов оказывают следующие характеристики материалов, используемых для изготовления водоразрушаемых формообразующих элементов: прочностные, упругие, деформационные, теплофизические и так далее.

В результате экспериментальных исследований по определению уровня контактных давлений и анализа напряженно-деформированного состояния в системе «формообразующий элемент (оправка) - оболочка» был сформирован комплекс необходимых характеристик материала для водоразрушаемых формообразующих элементов.

В нашей предыдущей работе сделан подробный анализ технологии изготовления водоразрушаемых формообразующих изделий, например, литейных стержней, применяемых при литье металлов и пластмасс, а также изделий типа «кокон» и корпусов ракетных двигателей на твердом топливе ${ }^{4}$. Было показано, что они могут быть использованы для изготовления водорастворимых оправок, применяемых при изготовлении изделий из полимерных композиционных материалов методом намотки или выкладки с использованием связующих, требующих повышенных температур отверждения и в условиях механических напряжений. Проведен анализ возможного использования различных водоразрушаемых материалов для создания подобных изделий. Проанализированы свойства водоразрушаемых композиционных материалов на основе жидкого стекла и возможности их использования для изготовления оправок. На основе проведенного анализа сделан выбор основы для изготовления основы для изготовления оправок на основе водоразрушаемых материалов. Проведен анализ физикомеханических свойств галогенидов щелочных металлов и произведен обоснованный выбор веществ основы, подходящих для изготовления водоразрушаемых композиционных материалов.

${ }^{4}$ Kudryavtsev P. Composite materials for manufacture of water destroyable form-forming equipment. Journal "Scientific Israel- Technological Advantages". Vol. 20, № 1, 2018, pp. 40-45, ISSN: 1565-1538. 
Предложена рецептура и технология изготовления изделий из водоразрушаемых материалов. Проведен анализ процессов при разрушении этих материалов после их использования.

Таким образом, становятся актуальными разработка научных основ получения материалов для изготовления водоразрушаемых формообразующих элементов с заданными свойствами и поиск методов целенаправленного регулирования их свойств. Опыт предыдущих исследований показывает, что такие разработки возможны на основе представлений физико-химической механики дисперсных структур. Начало развитию исследований в этом направлении было положено в работах П.А. Ребиндера и его школы 5 .

\section{1. Водоразрушаемые композиционные материалы \\ на основе жидкого стекла для изготовления оправок}

Натриевое жидкое стекло широко применяется в литейном производстве для изготовления литейных форм и различных формовочных смесей. Для проведения экспериментов было использовано высокомодульное натриевое жидкое стекло с силикатным модулем $\mathrm{n}=2.7 \div 3,0$ и выше, плотность стекла $1400 \div 1420 \kappa 2 / \mathrm{M}^{3}$. Процесс отверждения жидкого стекла сопровождался проявлением адгезионных свойств к наполнителю кварцевому песку и осуществлялся при естественном (на воздухе) или искусственном (нагревом, продувкой теплого воздуха) высушивании смеси. В отличие от изготовления литейных форм ${ }^{6}$, в данном процессе старались максимально избежать разрушения жидко-стекольной основы, чтобы в дальнейшем не уменьшить растворимость его в воде.

Кроме этого, для достижения высокой прочности такого материала необходимо добиваться наиболее плотной упаковкой зерен песка. Для

${ }^{5}$ Ребиндер П.А. Поверхностные явления в дисперсных системах. Физикохимическая механика: Избр. тр. Москва : Химия, 1979; Абрамсон А.А. и Щукин Е.Д. (ред.). Поверхностные явления и поверхностно-активные вещества. Москва : Химия, 1984.

6 Жуковский С.С., Лясс А.М. Формы и стержни из холоднотвердеющих смесей. Москва : Машиностроение, 1978. 24 с.; Корнеев В.И., Юргинсон Е.Н., Кузьмин Б.А. Опыт разработки и применения связующих для легковыбиваемых формовочных смесей. Ленинград : ЛДНТП, 1986. 26 с.; Kudryavtsev P., Figovsky O. Advanced Nanomaterials Based on Soluble Silicates. Journal Scientific Israel Technological Advantages, Vol. 16, № 3, 2014, p. 38-76. 
этого, помимо давления формования, требуется использование наполнителя с определенным распределением зерен по размерам и использование жидкого стекла с оптимальной вязкостью. При этом для получаемых материалов их прочность зависит от содержания жидкого стекла в системе. Эта зависимость проходит через острый максимум, и ее вид представлен на Рисунке 2.

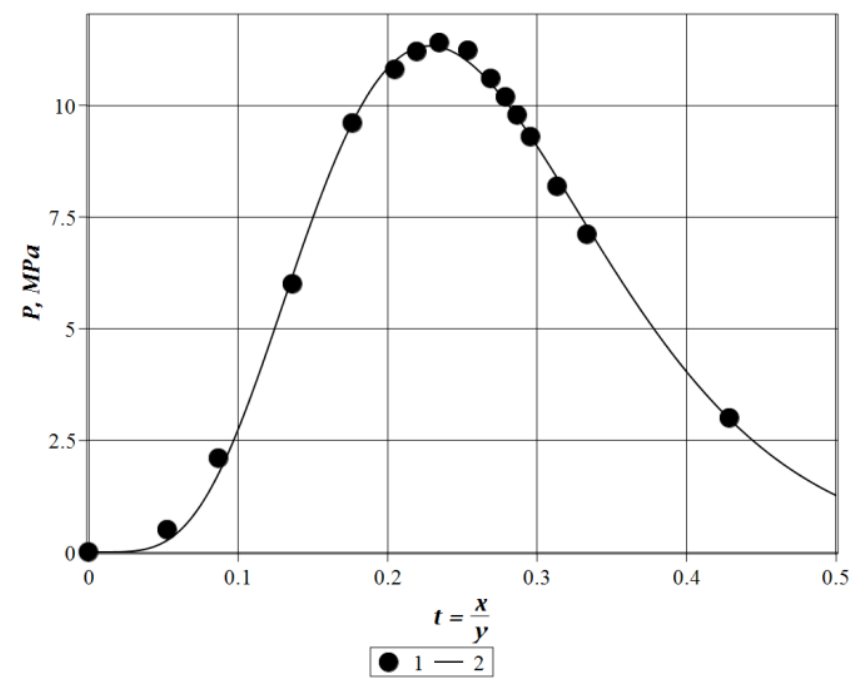

Рисунок 2. Зависимость предела прочности на разрыв композиционного материала от содержания жидкого стекла $\left(\mathrm{Na}_{2} \mathrm{O} \cdot 3,3 \mathrm{SiO}_{2}, \rho=1,392 / \mathrm{cm}^{3}\right)$ в утрамбованной вибрацией смеси с кварцевым песком $(0,625$ мм $)$ после сушки до постоянного веса при $130^{\circ} \mathrm{C}: \mathrm{P}$ - Разрушающее напряжение при сжатии для образцов композиционного материала, МПа. $\boldsymbol{x}$ - содержание жидкого стекла в композиции, масс. $\% ; y$ - содержание кварцевого песка, масс.\%.

1 - экспериментальные точки; 2 - аппроксимирующая функция

Для повышения технологичности изготовления материала и повышения скорости его растворения после использования необходимо снижение содержания жидкого стекла в композиции, при одновременном сохранении ее прочностных свойств. В связи с этим были применены дополнительные действия для увеличения плотности композиции. Максимальная плотность была достигнута применением полидисперсной песчаной смеси, снижением 
концентрации жидкого стекла и применением метода прессования сырой смеси при давлении 1,0 $\div 1,2$ МПа. Данные действия позволили снизить содержание жидкого стекла в композиции.

Таким образом, была разработана композиция следующего состава: кварцевый песок $87 \%$, молотый кварцевый песок $8 \%$, жидкое стекло 5\%. Прочность полученного композиционного материала после высушивания составила $5 \div 8$ МПа, при испытании на изгиб. После изготовления корпуса РДТТ оправку удавалось вымыть в течение нескольких часов.

Наиболее существенным путем улучшения разрушаемости жидкостекольных композиций, применяемых для изготовления оправок, является снижение содержания жидкого стекла в исходной смеси. Опыт производства показал, что улучшение разрушаемости таких смесей становится заметным при снижении массовой доли

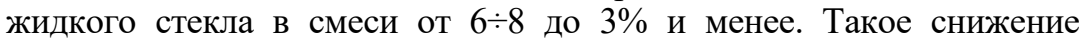
содержания связующего жидкого стекла в смеси, без ухудшения ее прочностных свойств возможно при условии повышения вяжущих свойств связующего или разработке новых вяжущих композиций на его основе.

Основными путями снижения содержания жидкого стекла в композициях являются:

- повышение стабильности состава и свойств жидкого стекла;

-повышение качества формовочных песков, прежде всего с позиций содержания пылевидных фракций;

- применение специальных приемов активации поверхности зерен кварцевого песка, обеспечивающих проявление высокопрочных адгезионных контактов на границе «жидкое стекло - кварц»;

- оптимизация технологических приемов приготовления смесей с позиций обеспечения полного и своевременного взаимодействия компонентов смеси. Сюда входит последовательность введения компонентов, способы их введения и так далее;

- совершенствование аппаратурного оформления, которое обеспечивает тщательное смешение компонентов смеси при низком содержании жидкого стекла и низкой влажности приготавливаемой смеси;

- обеспечение условий равномерного распределения давления при прессовании изделий, что особенно важно для крупногабаритных изделий;

- направление улучшения разрушаемости композиций на основе жидкого стекла включает принципиальное изменение состава и физико-химической природы жидкого стекла. Реализация такого 
подхода возможна за счет перехода в область высокомодульных жидких стекол (полисиликатов), со значением силикатного модуля $4 \div 10$ и снижения содержания примесей кальция и алюминия.

В качестве перспективной модифицирующей добавки, для создания композиционных материалов на основе жидкого стекла предложены технические лигносульфонаты ${ }^{7}$. Наши исследования показали, что лигносульфонаты оказывают существенное воздействие на процессы твердения и структурирования композиций на основе жидкого стекла. Они улучшают прочностные показатели материала. Введение в состав жидкого стекла $3 \%$ лигносульфонатов с повышенными молекулярными массами приводит к получению тонкопористой структуры формирующегося геля, высокой водонепроницаемости, прочности материала и достижению высоких эксплуатационных показателей.

Однако связующие материалы на основе жидкого стекла в обычных условиях на воздухе отверждаются необратимо в результате взаимодействия щелочной силикатной составляющей с $\mathrm{CO}_{2}$ воздуха. Проблема ухудшения растворимости композитов, после завершения всех технологических циклов, была решена с использованием в качестве основы композита - галогенидов щелочных металлов.

\section{2. Выбор основы для изготовления основы для изготовления оправок на основе водоразрушаемых материалов}

Как известно, все галургические производства имеют большую проблему, связанную со слеживаемостью минеральных солей, особенно при их транспортировке. Слеживаемость - это свойство порошкообразных веществ, характеризующее их склонность к переходу в связанное, уплотненное состояние ${ }^{9}$. Прочность брикета соли называется степенью слеживаемости. Ее величину обычно измеряют в единицах давления ( $\kappa П а)$, при котором монолитный образец определенной формы разрушается. Слеживаемость зависит от гранулометрического состава, влажности вещества, наличия примесей и других факторов. Минимальная влажность вещества, выше которой продукт может слеживаться, обычно составляет от

7 Lebo, S.E., Gargulak, J.D. and McNally, T.J. Lignin. Kirk-Othmer Encyclopedia of Chemical Technology, John Wiley \& Son, (2001).

${ }^{8}$ Kudryavtsev P., Figovsky O. Advanced Nanomaterials Based on Soluble Silicates. Journal Scientific Israel - Technological Advantages, Vol. 16, № 3, 2014, p. $38-76$.

Терещенко А.Г. Гигроскопичность и слеживаемость растворимых веществ. Изд-во Томского политехнического университета, 2011. 79 с. 
0,05 до 1 масс.\%. Гигроскопические процессы и процессы слеживаемости растворимых веществ являются двумя сторонами одного и того же массообменного процесса, в котором участвуют газовая, жидкая и твердая фазы.

Слеживаемость - это свойство дисперсного вещества, связанное с процессом переноса воды из межкристаллитной жидкой фазы в газовую фазу, при одновременном выделении из жидкой фазы твердого вещества в зоне контакта отдельных кристаллов. Таким образом, кристаллические мостики между кристаллами растворимого вещества возникают только при высушивании вещества. Явление слеживаемости определяется не влажностью продукта, а десорбцией влаги из влажного продукта. Избыточная влажность продукта - это только необходимое условие процесса слеживаемости. Механизм слеживаемости через образование кристаллических мостиков при прохождении гигроскопических процессов является основным для растворимых веществ. Однако на этот основной процесс могут накладываться и другие реакции. Например, возможно образование солевых мостиков при охлаждении влажного продукта. Также возможно влияние химических реакций, продолжающихся после изготовления продукта, в том числе связанных с образованием кристаллогидратов. Большой эффект оказывает увеличение площади контакта между гранулами за счет мелкодисперсной фракции. Кроме того, слеживаемость может возникать в результате деформации частиц соли под действием механических нагрузок и разрушения частиц под действием внешних усилий и другое.

Существует большое количество работ, посвященных борьбе с этим эффектом ${ }^{10}$. Однако мы решили усилить этот эффект и

10 Терещенко А.Г. Гигроскопичность и слеживаемость растворимых веществ, Изд-во Томского политехнического университета, 2011. 79 с.; Хамский Е.В. Кристаллические вещества и продукты. Методы оценки и совершенствования свойств. Москва : Химия, 1986, 224 с.; Волков В.А. Разработка технологии основ неслеживемости хлорида калия. Автореферат канд. дисс., Ленинград, 1986.; Пойлов В.3. Основы технологий некоторых кристаллических продуктов с заданными свойствами. Автореферат докт. дисс., Пермь, 1998; Черепанова М.В., Потапов И.С., Пойлов В.З., Попова К.В., Алиферова С.Н. Влияние условий хранения и транспортировки на физикомеханические свойства гранулированного хлорида калия. Вестник ПНИПУ. Химическая технология и биотехнология. 2012. №13.; Zurimendi J., Bolivar C.; Rafael A. Anti- caking composition. United States Patent № 4,772,308, Current International Class: B01J 2/30; C05C 1/02; C05C 1/00; C05G 003/00; C05C 001/02; C05C 003/00. 20.09.1988; Юркина М.И. Исследование процесса устранения слеживаемости хлористого калия с помощью добавок ферроцианида и аминов : автореферат канд. дисс., Пермь, 1974. 
использовать его для создания водоразрушаемых конструкционных композиционных материалов. Выбирая конкретные основы для изготовления материалов оправок, необходимо учитывать следующие факторы. Используемые для этих целей соли не должны образовывать кристаллогидраты. Это обусловлено тем, что кристаллогидраты способны выделять воду при достаточно низких температурах и соответственно растворяться в своей же кристаллогидратной воде. Такой эффект характерен, например, для Глауберовой соли, мирабилита $-\mathrm{Na}_{2} \mathrm{SO}_{4} \cdot 10 \mathrm{H}_{2} \mathrm{O}^{11}$. Другим недостатком кристаллогидратных солей является возможность их гидролиза и большая усадка при потере воды. Еще одним недостатком некоторых солей, который исключает возможность их применения в качестве основы для изготовления оправок, является наличие фазовых переходов при температурах в диапазоне от комнатной до температуры эксплуатации.

Таким образом, соли, которые пригодны для такого использования, должны быть достаточно дешевыми и широко распространенными в природе. Кроме того, они должны иметь высокую растворимость в воде. Такими свойствами обладают вещества, имеющие преимущественно ионную кристаллическую решетку. Из множества подобных соединений можно выделить группу галогенидов щелочных, щелочноземельных металлов и аммония. Однако из этой группы мы удалим галогениды щелочноземельных металлов, так как последние обладают высокой гигроскопичностью и образуют множество кристаллогидратов. Это свойство, как мы уже отмечали, является недостатком при решении поставленной задачи.

В настоящее время природа механических свойств ионных кристаллов изучена значительно лучше, чем каких-либо других кристаллов. Одна из причин хорошего понимания свойств ионных кристаллов это простая природа химической связи, которая обуславливает их структуру и свойства. Другая - заключается в том, что пластическую деформацию в этих кристаллах можно было изучать очень детально путем непосредственного наблюдения наличия и движения дислокаций в их структуре. Пластическое течение и хрупкое разрушение являются гетерогенными процессами, поэтому, измерением только гомогенных механических параметров, таких, как напряжение, деформация и скорость деформации, невозможно достичь существенного понимания этих

${ }^{11}$ Hill, J.C. Johann Glauber's discovery of sodium sulfate. Sal Mirabile Glauberi. Journal of Chemical Education. 1979, Vol.56, No 9, p. 593. 
явлений. Для того чтобы правильно связать гомогенные параметры с явлениями атомного масштаба, необходимо иметь возможность изучать неоднородности - дислокации и трещины - сами по себе. Большой прогресс в этой области был достигнут еще в конце прошлого века ${ }^{12}$. Некоторые свойства ионных кристаллов обусловлены тем, что они состоят из локально заряженных ионов, однако большая часть механических свойств, имеет прямую аналогию со свойствами металлических и ковалентных кристаллов.

Силы связи в идеальном ионном кристалле являются исключительно электростатическими, так что наиболее устойчивыми структурами оказываются плотно упакованные решетки типа хлористого натрия или решетки типа хлористого цезия. Кроме того, так как силы связи зависят только от расстояния между ионами и не зависят от углов между соседями, упругие постоянные должны подчиняться соотношениям Коши для линейных деформаций $35^{13}$. Этот факт сужает число интересующих нас веществ до нескольких щелочно-галоидных кристаллов, включая $\mathrm{NaCl}$. Однако мы не будем полностью ограничиваться этим списком, а рассмотрим некоторое количество щелочно-галоидных кристаллов и несколько других кристаллов, которые имеют решетку типа хлористого натрия. Кристаллы галогенидов рубидия и цезия рассматриваться не будут вследствие того, что они сравнительно мало исследованы и не могут быть применены для наших целей ввиду своей редкости и дороговизны.

Свойства щелочно-галоидных кристаллов изучены достаточно хорошо. Такие величины, как энергия связи и упругие постоянные, могут быть рассчитаны с приемлемой точностью из свойств атомов, составляющих эти кристаллы. Упругие постоянные являются наиболее важными механическими параметрами кристаллов, так как от них зависят все другие механические свойства. Например, у кристаллов с малым модулем упругости обычно трудно ожидать большого сопротивления пластическому течению.

Энергия кристаллической решетки определяется балансом сил притяжения и отталкивания ионов, образующих данную решетку. Основную часть энергии связи этих кристаллов составляет простое электростатическое взаимодействие между ионами, а изменение

12 Гилман Дж., Механические свойства ионных кристаллов. Усnехи физических наук. 1963 т. 80, вып. 7, с. 455-503.

13 Коробов В.И., Очков В.Ф. Химическая кинетика. Введение с Mathcad/ Maple/MC5, М., Горячая линия -Телеком, 2009, 384 с. 
электростатической энергии при деформации дает основной вклад в модули упругости. Стабильность структуры ионных кристаллов определяется балансом сил притяжения и отталкивания. Энергия отталкивания в ионных кристаллах возникает по двум причинам. Этими причинами являются силы отталкивания, которые появляются, когда электронные облака ионов начинают перекрываться при достаточно тесном сближении ионов друг с другом при образовании кристалла.

Первая причина заключается в том, что перекрытие электронных облаков должно приводить к уменьшению величины заряда отрицательного иона за счет каждого соседнего положительного иона и наоборот. Этот эффект уменьшает притяжение между ионами при уменьшении расстояния между ними.

Вторая причина заключается в том, что при перекрытии электронных облаков уменьшается объем, в котором могут двигаться электроны. Согласно принципу неопределенности Гейзенберга, это означает, что кинетическая энергия электронов должна возрастать, и таким образом полная энергия системы стремится увеличиться, вызывая отталкивание ионов.

Существует довольно хорошее согласие между результатами полуэмпирической теории Борна - Майера, квантово-механической теории и экспериментальными данными энергии сил связи в щелочно-галоидных кристаллах, приведенных в работах $^{14}$. На рисунке 3 представлены эти данные в зависимости от обратной величины расстояния между ближайшими соседями в кристаллической решетке соответствующих галогенидов щелочных металлов.

Представленные на рисунке 3 данные указывают на существование хорошей обратно пропорциональной зависимости энергии сил связи обратной величины расстояния между ближайшими соседями в кристаллической решетке. Если энергию электростатического взаимодействия одного иона $U_{i}$ в ионном кристалле представить, как было указано в работе ${ }^{15}$, в виде

14 Гилман Дж., Механические свойства ионных кристаллов, Успехи физических наук, 1963 т. 80, вып. 7, с. 455-503; Hearmon R.F.S. The Elastic Constants of Anisotropic Materials, Rev. Mod. Phys., 1946, Vol. 18, Issue 3, p. 409; Slaughter W.S. The Linearized Theory of Elasticity, Springer, 2002, 512 p. ISBN: 978-1-4612-6608-2

${ }^{15}$ Morris D.F.C., The lattice energies of the alkali halides, Acta Cryst. Vol. 9, 2, p. 197 (1956). doi: 10.1107/S0365110X56000498 
уравнения в соответствии с законом Кулона, то получим выражение:

$$
U_{i}=\frac{z_{i} e^{2}}{4 \pi \varepsilon_{0}} \sum_{j \neq i} \frac{z_{j}}{r_{i j}}
$$

Где $r_{i j}=\left|r_{i}-r_{j}\right|$ расстояния между ионами $i$ и $j, z_{j}-$ заряд иона $j$, $e$ - заряд электрона, $\varepsilon_{0}$ - электрическая постоянная.

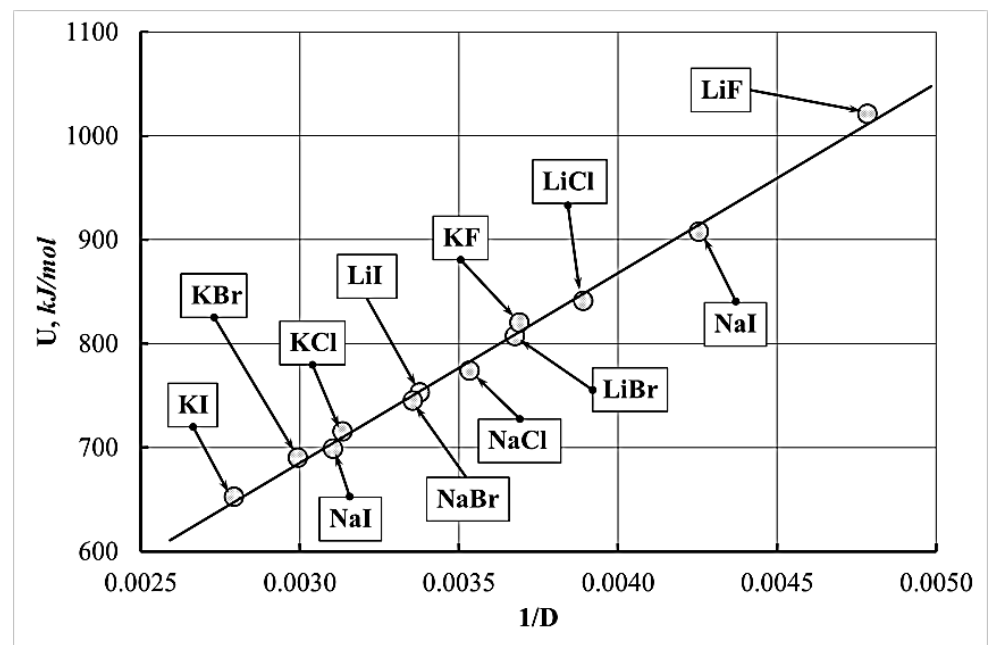

\section{Рисунок 3. Корреляция энергии сил связи щелочно-галоидных} кристаллов ${ }^{16}$ от обратной величины расстояния между ближайшими соседями в кристаллической решетке $\left(D=r_{c a t}+r_{a n}\right)$. Ионные радиусы взяты по шкале кристаллографических ионных радиусов в единицах $\mathrm{pm}^{17}$

При нормировке расстояния между ионами на величину расстояния между ближайшими противоположно заряженными ионами $D$ (которое зависит от параметров кристаллической

16 Гилман Дж., Механические свойства ионных кристаллов. Успехи физических наук. 1963 т. 80, вып. 7, с. 455-503; Hearmon R.F.S. The Elastic Constants of Anisotropic Materials, Rev. Mod. Phys., 1946, Vol. 18, Issue 3, p. 409. $541 \mathrm{p}$.

${ }^{17}$ Harrison W.A. Solid State Theory. Dover Publications, Inc. New York, 1980. 
решётки, типа структуры кристалла и ионных радиусов структурных элементов), получим:

$$
U_{i}=\frac{z_{i} e^{2}}{4 \pi \varepsilon_{0}} \sum_{j} \frac{z_{j}}{r_{i j} / D}=\frac{z_{i} e^{2}}{4 \pi \varepsilon_{0} D} M
$$

где $M-$ постоянная Маделунга.

Для кристаллической решётки типа $\mathrm{NaCl}$, с зарядами ионов \pm 1 и координационным числом 6, константа Маделунга имеет величину $M=1,747558$. Для структур типа $\mathrm{CsCl}$ с координационным числом 8 она несколько выше и составляет величину $M=1,763$. Таким образом, для большинства галогенидов щелочных металлов должна соблюдаться обратно пропорциональная зависимость энергии сил связи от расстояния на расстояние между ближайшими разноименно-заряженными ионами. Этот факт и наблюдается на Рисунке 3.

Энергия сил связи является фундаментальной характеристикой, напрямую связанной с упругими постоянными и прочностными характеристиками кристаллов. Упругие постоянные можно грубо оценить следующим образом. Сила $F$, с которой один ион действует на другой, в зависимости от $r$ - расстояния между ними, будет равна: $F=\frac{\partial U}{\partial r}$. Таким образом, напряжение будет примерно равно:

$$
\sigma \sim \frac{1}{D^{2}} \frac{\partial U}{\partial r}
$$

При этом дифференциал напряжения в зависимости от $r$ будет иметь вид

$$
d \sigma=\frac{d r}{D^{2}}\left(\frac{\partial^{2} U}{\partial r^{2}}\right)
$$

Однако дифференциал напряжения представляет собой величину

$$
d \sigma=E d \varepsilon
$$

где $E$ - модуль упругости; $d \varepsilon=\frac{d r}{D}$ дифференциал деформации. Отсюда получаем итоговое соотношение для модуля упругости 


$$
E=\frac{1}{D}\left(\frac{\partial^{2} U}{\partial r^{2}}\right) \approx \frac{z_{i} e^{2} M}{2 \pi \varepsilon_{0} D^{4}}=c \cdot D^{-4}
$$

Упругие постоянные являются наиболее важными механическими параметрами кристаллов, так как от них зависят все другие механические свойства. Например, у кристаллов с малым модулем упругости обычно трудно ожидать большого сопротивления пластическому течению и разрушению.

Значения упругих постоянных, определенные экспериментально, приведены в обзорах ${ }^{18}$ и частично были измерены нами. На рисунке 4 представлены средние значения модулей упругости для кристаллов галогенидов щелочных металлов и аммония. Представленные данные были получены при комнатной температуре.

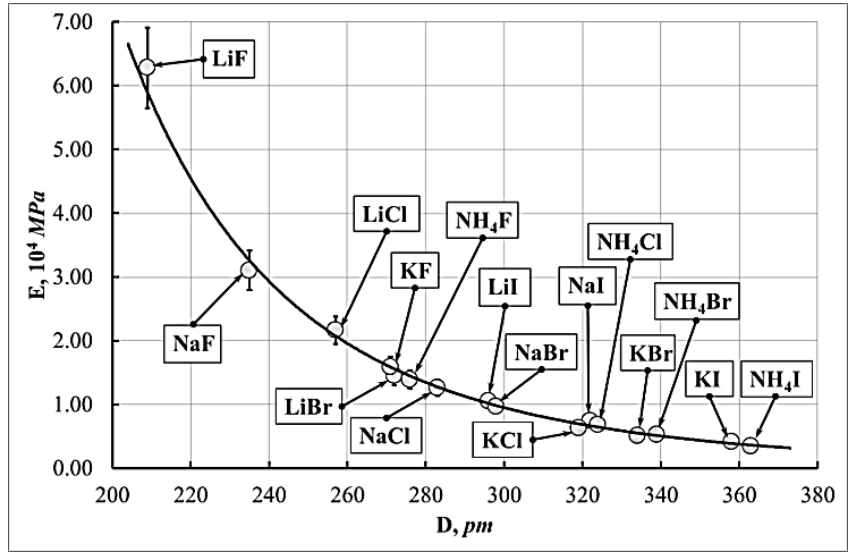

Рисунок 4. Зависимость модуля упругости кристаллов галогенидных солей щелочных металлов и аммония в зависимости от расстояния между ближайшими соседями в кристаллической решетке $\left(D=r_{c a t}+r_{a n}\right)$. Ионные радиусы взяты по шкале кристаллографических ионных радиусов в единицах $\mathrm{pm}^{19}$

${ }^{18}$ Hearmon R.F.S. The elastic constants of anisotropic materials-II, Advances in Physics, 1956, Vol. 5, Issue 19, p. 323-382; Huntington H.B. The Elastic Constants of Crystals, Solid State Physics, 1958, Vol. 7, p. 213-351; Фурман А.А., Шрайбман C.С. Приготовление и очистка рассола, Москва, «Химия», 1966, 232 с.

19 Harrison W.A. Solid State Theory. Dover Publications, Inc. New York, 1980. 541 p.; Brazhkin V.V., Grimsditch M., Guedes I., Bendeliani N.A., Dyuzheva T.I., Lityagina L.M. Elastic moduli and the mechanical properties of stishovite single crystals, Phys. Usp. Vol. 45, p. 447-448, 2002; DOI: 10.1070/PU2002v045n04ABEH001162 
Представленные на рисунке данные могут быть аппроксимированы следующим выражением

$$
E=a \cdot D^{-b}
$$

Коэффициенты этого уравнения, рассчитанные по методу наименьших квадратов, имеют величину $a=3,00 \cdot 10^{+16}, b=5,05$. Некоторое различие значений показателя степени от расстояния между ближайшими соседями в кристаллической решетке, полученной теоретически и на основе экспериментальных данных, указывает на то, что теоретические выкладки были сделаны с некоторыми допущениями и не учитывают всей полноты факторов, оказывающих влияние на механические свойства кристаллов галогенидных солей. Однако в целом данные результаты дают близкую тенденцию, так как различие в показателях степени в размере примерно 20\% не является критичным. Поэтому на основе этих представлений можно уже сделать качественные предсказания поведения тех или иных веществ и осуществлять выбор веществ, подходящих для создания требуемых материалов.

В результате анализа представленных выше данных из огромного множества минеральных солей можно остановиться на двух их представителях. Такими подходящими солями являются хлориды натрия и калия. У этих солей достаточно хорошо изучены их механические и физические свойства, что дает хорошую перспективу для создания водоразрушаемых материалов на их основе.

Рассматривая вопрос изготовления материалов для оправок из композитов на основе галогенидов щелочных металлов, необходимо остановится на их механических и физико-химических свойствах. Механическим свойствам кристаллов галогенидов щелочных металлов, и, в частности, хлорида натрия, посвящено много работ. Еще А.Ф. Иоффе в своей работе ${ }^{20}$ подробно обсуждал механические свойства хлорида натрия. Он обратил внимание на тот факт, что в наибольшем противоречии с предсказаниями электрической теории кристаллических решеток оказывается прочность твердых тел. Максимальная величина связи в кристаллах $\mathrm{NaCl}$ на основании теории кристаллических решеток получается порядка 3000 МПа для

${ }^{20}$ Иоффе А.Ф. Избранные труды. Том І. Механические и электрические свойства кристаллов. Изд-во «Наука», Ленингр. отд., Ленинград, 1974, стр. 1-327. 
случая всестороннего растяжения. Одностороннее растяжение при комнатной температуре должно дать около 2000 МПа. Однако наблюденная прочность отдельных кристаллов $\mathrm{NaCl}$ на растяжение среднем составляет 4,3 МПа. Понижение температуры до температуры жидкого азота $\left(-195,75^{\circ} \mathrm{C}\right)$ не влияет заметным образом на прочность каменной соли. Также она практически не изменяется при нагреве до $200^{\circ} \mathrm{C}$ (Рисунок 5).

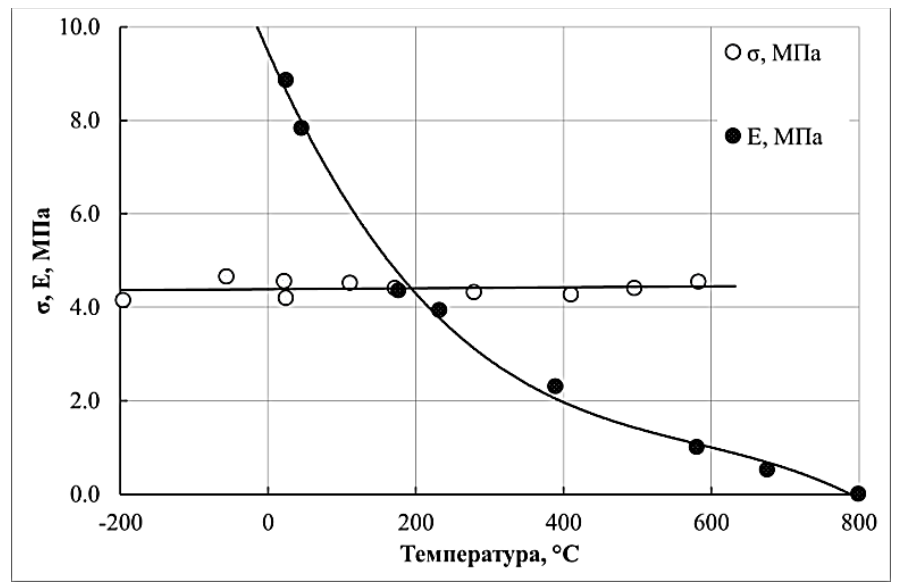

\section{Рисунок 5. Температурная зависимость предела прочности (б) и модуля упругости (Е) кристаллов $\mathrm{NaCl}^{21}$}

Следует обратить внимание на то, что в реальных материалах прочность измерялась не на одиночных кристаллах, a на кристаллических композициях. Это объяснялось тем, что при $200^{\circ} \mathrm{C}$ предел упругости кристалла падает до 4,3 МПа, то есть равен пределу прочности. Таким образом, при температурах выше $200^{\circ} \mathrm{C}$ предел упругости оказывается ниже предела прочности. При увеличении нагрузки вначале достигается предел упругости, и начинается пластическая деформация, нарушающая решетку кристалла. Как было обнаружено еще А.Ф. Иоффе, процесс пластической деформации значительно увеличивает прочность кристалла ${ }^{22}$.

${ }^{21}$ Иоффе А.Ф. Избранные труды. Том I. Механические и электрические свойства кристаллов. Ленинград : Изд-во «Наука», 1974. стр. 1-327.

${ }^{22} \mathrm{CM}^{21}$ 
Прочность одиночных кристаллов на растяжение примерно в 500 раз меньше, чем вычисленный максимум для сил сцепления, и разрыв наступает прежде, чем может быть замечено существенное отклонение от закона Гука. Даже пластически деформированные кристаллы обладают в 40 раз меньшей прочностью, чем следовало бы ожидать. Наблюдаемый разрыв при растяжении не имеет ничего общего с истинной прочностью. Можно легко понять, что постепенный частичный разрыв требует гораздо меньшей силы, чем разрыв одновременно по всему поперечному сечению. Допустим, например, что на боковой поверхности растянутого стержня существует малая, но очень резкая трещина. Распределение усилий будет таково, что на краю трещины усилие будет чрезвычайно концентрированным. Если радиус кривизны дна трещинки достаточно мал, отношение усилия у края трещины к среднему усилию на все поперечное усилие может оказаться весьма большим, что имеет место в реальном кристалле.

Если этим объясняется малая прочность кристаллов на растяжение, то, очевидно, состояние поверхности, с которой начинаются надрыв и разрушение образца, должно играть существенную роль: в таком случае необходимо найти еще объяснение тому факту, что наблюдаемая прочность на растяжение постоянна в пределах 10\%. Влияние состояния поверхности на прочность каменной соли впервые было показано в 23 . Прочность кристаллов каменной соли зависит не только от ориентации усилия, но и от ориентации внешних поверхностей, ограничивающих кристалл.

А.Ф. Иоффе с сотрудниками обнаружили эффект, который в дальнейшем получил его имя ${ }^{24}$. Ими было обнаружено, что прочность кристаллов каменной соли значительно возрастала при их погружении в горячую воду. Предел прочности возрастал до 300 и даже до 1600 МПа. Эти значения уже близко подходят к теоретической прочности 2000 МПа. Прежде чем наступал разрыв, достигался предел упругости, соответствующий при комнатной температуре 9 МПа, и в

${ }^{23}$ Joffe A., Lewitzky M. Über die Kohäsionsfestigkeit von Steinsalz, Zeitschrift fur Physik. 1929, Bd. 35. S. 442-445.

24 Иоффе А.Ф. Избранные труды. Том I. Механические и электрические свойства кристаллов. Изд-во «Наука», Ленингр. отд. Ленинград, 1974. стр. 1-327; Фурман А.А., Бельды М.П., Соколов И.Д. Поваренная соль. Производство и применение в химической промышленности. Москва : Химия, 1989. 272 c.; Schmid B., Boas W., Crystal Plasticity, Springer, Berlin, 1936. 
момент, когда происходил разрыв, кристалл оказывался пластически деформированным. Измерявшаяся прочность была, таким образом, не прочностью одиночного кристалла, а прочностью поликристаллического образования. Тем не менее, этот результат является существенным, ибо он показывает, что внутренняя прочность каменной соли не меньше 1600 Mna, и что кристаллы каменной соли могут выдержать подобные усилия.

А.Ф. Иоффе действие воды и эффекта растворения видел в следующем. При растяжении соли в воде растворяется ее поверхность. Растворение поверхности влечет за собой удаление поверхностных трещин и поверхностных дислокаций, на которых возникают локальные перенапряжения, ведущие к разрыву. Если удалить дефекты растворением, можно нагрузить кристалл до напряжений, превышающих его хрупкую прочность, и довести их до значений, соответствующих пределу упругости. При достижении напряжений, соответствующих пределу упругости, наступает пластическая деформация, сопровождающаяся большим удлинением и упрочнением материала. Растворение ведет к повышению величины хрупкой прочности до значения, соответствующего величине предела упругости. Повышенная пластичность соли в воде является следствием возможности перевода ее выше предела упругости ${ }^{25}$.

Поверхностные условия не оказывают болышого влияния на основной для пластичности фактор, а именно на подвижность дислокаций. Было обнаружено ${ }^{26}$, что предел текучести кристаллов $\mathrm{NaCl}$ не чувствителен к поверхностным условиям, а напряжение, требуемое для движения дислокации в кристалле $\mathrm{NaCl}$, не зависит от выдержки на воздухе, в воде и в масле ${ }^{27}$. Обработка поверхности влияет на наклон диаграммы напряжение - деформация в области деформационного упрочнения ${ }^{28}$. Важным выводом является то, что эффект Иоффе является следствием устранения больших

${ }^{25}$ Schmid B., Boas W., Crystal Plasticity, Springer, Berlin, 1936.

${ }^{26}$ Бугаенко Л.Т., Рябых С.М., Бугаенко А.Л. Почти полная система средних ионных кристаллографических радиусов и ее использование для определения потенциалов ионизации. Вестник Московского университета. Серия 2: Химия. 2008, Т. 49, № 6, с. 363-385.

27 Гилман Дж., Механические свойства ионных кристаллов. Успехи физических наук. 1963 т. 80, Вып. 7, с. 455-503.

${ }^{28}$ Бугаенко Л.Т., Рябых С.М., Бугаенко А.Л. Почти полная система средних ионных кристаллографических радиусов и ее использование для определения потенциалов ионизации. Вестник Московского университета. Серия 2: Химия. 2008, T. 49, № 6, c. 363-385. 
поверхностных дефектов путем растворения кристалла. Если кристалл, предварительно смоченный, тщательно высушить, не дав ему реагировать с воздухом, он остается пластичным почти неограниченно долго. С другой стороны, если в массе присутствуют твердые частицы, то они могут быть центрами возникновения трещин в кристалле ${ }^{29}$.

Эффект Иоффе также был нами использован при разработке водоразрушаемых конструкционных материалов. При этом этот эффект был дополнительно усилен за счет введения в состав композиции дополнительных веществ, которые выступают как поверхностно активные продукты, создавая на поверхности кристаллов соли защитную пленку. Также были введены добавки, которые изменяют свойства водно-солевых растворов, регулируя процесс кристаллизации соли при их выпаривании.

\section{3. Водоразрушаемые композиционные материалы на основе} галогенидов щелочных металлов для изготовления оправок

Авторами были запатентованы водоразрушаемые композиционные материалы на основе галогенидов щелочных металлов для изготовления оправок ${ }^{30}$. Реализация идеи, заложенной в данном патенте, позволяет повысить прочность формообразующих изделий. Это привело к снижению брака при производстве отливок и корпусов изделий типа «кокон». При этом удалось повысить удельное давление литья и намотки, тем самым была расширена номенклатура изготовляемых изделий. Применение новых материалов позволило снизить вес оправок, при сохранении заданных прочностных показателей. Кроме того, удалось снизить расход дорогостоящих материалов и улучшить экономические показатели производства.

Настоящая работа относится к материаловедению для машиностроения, а именно к изготовлению водорастворимых формообразующих изделий, например, литейных стержней, применяемых при литье металлов и пластмасс, и может быть использовано для изготовления водорастворимых оправок, применяемых при намотке или выкладке изделий из полимерных композиционных материалов с использованием связующих,

${ }^{29}$ См. ${ }^{24}$

${ }^{30}$ Кудрявцев П.Г. Журавлев С.Г., Ботов В.А., Клячкин Ю.С., Лавров Л.Н., Ипанова О.П., Новгородцева М.М., Шафит Я.М., Леонов А.А., Радушев А.В., Бегишев В.П. Композиция для изготовления водорастворимых формообразующих изделий, А.С. СССР № 1696097 по заявке № 4634416/33 от 9.01.89, опубл. Б.И. №45 от 07.12.91. 
требующих повышенных температур отверждения. Целью работы является повышение прочности, снижение коэффициента температурного расширения состава и снижение стоимости изготовления соответствующих продуктов.

В качестве основы для создания материала была выбрана водорастворимая соль, хлорид натрия. В дополнение к водорастворимой соли разработанная композиция включает различные добавки, которые служат в качестве суперпластификаторов, высаливающих агентов, а в качестве растворителя композиция содержит воду.

По аналогии с бетонными смесями в состав разработанной композиции вводится суперпластификатор. Основной функцией суперпластификатора является значительное повышение подвижности готовой к применению смеси. Использование суперпластификаторов в составе разработанной смеси в комбинации с другими модифицирующими добавками позволяет создавать пластичные композиции, предназначенные как для вибрационного, так и для механического прессования готовых изделий.

В качестве суперпластификатора использованы модифицированные технические лигносульфанаты. Механизм действия суперпластификатора упрощенно можно представить следующим образом. Так как суперпластификаторы относятся к поверхностно активным веществам, то их основное свойство заключается в том, что молекулы таких веществ адсорбируются на поверхности частиц соли, образуя тонкий моно- или бимолекулярный слой, при этом уменьшается межфазовая энергия сцепления и облегчается дезагрегация частиц соли. При этом вода, входящая в состав композиции, играет роль пластифицирующей смазки. В дополнение к этому эффекту, адсорбированный слой сглаживает шероховатость частиц соли, уменьшая тем самым коэффициент трения между ними. Кроме того, в результате адсорбции суперпластификатор создает одноименный электрический заряд на поверхности частиц твердой фазы и исключает возможность их сцепления за счет электростатических сил и дополнительно снижает вязкость суспензии. В процессе дегидратации происходит рост кристаллов соли. При этом постепенно прекращается отталкивающее действие одноименных электрического заряда, и суспензия теряет подвижность, она твердеет.

Добавки лигносульфонатов выполняют в композиции несколько функций. Они одновременно являются суперпластификаторами и связующими. Как суперпластификаторы, лигносульфонаты 
относятся к поверхностно активным веществам, и их основное свойство заключается в адсорбции на поверхности частиц соли, образуя тонкий моно- или бимолекулярный слой, при этом уменьшается межфазовая энергия сцепления и облегчается разрушение агрегатов, образованных частицами соли. При этом вода, входящая в состав композиции, играет роль пластифицирующей смазки. То, что лигносульфонаты еще выполняют и функцию связующего, стало понятно после их испытания при получении образцов на диоксиде кремния в качестве дисперсной фазы.

Использованные лигносульфонаты содержат в своем составе 85\% основного вещества в виде солей лигносульфоновых кислот с катионом, соответствующим основанию, использованному при варке целлюлозы, и до 15\% минеральных солей сернистой и серной кислот. Нами в экспериментах использовались технические лигносульфонаты с натриевым основанием производства Соликамского ЦБК по ОСТ 13-183-03 марки А. Лигносульфонаты или сульфированный лигнин представляют собой водорастворимые анионные полиэлектролиты. Они являются побочными продуктами производства древесной целлюлозы при использовании технологии сульфитной варки целлюлозы ${ }^{31}$.

Большая делигнификация в сульфитной варке включает кислотное расщепление эфирных связей, которые соединяют многие компоненты лигнина ${ }^{32}$. Электрофильные карбокатионы,

${ }^{31}$ Gargulak, J. D., Lebo, S. E. and McNally, T. J. (2015). Lignin. In Kirk-Othmer Encyclopedia of Chemical Technology, John Wiley \& Sons, Inc (Ed.). doi:10.1002/0471238961.12090714120914.a01.pub3; Pang B., Yang S., Fang W., Yuan T.-Q., Argyropoulos D.S., Sun R.-C., Structure-property relationships for technical lignins for the production of lignin-phenol-formaldehyde resins, Industrial Crops and Products, Vol. 108. 2017. P. 316-326. ISSN 0926-6690. URL: https://doi.org/10.1016/j.indcrop.2017.07.009.

${ }^{32}$ Pang B., Yang S., Fang W., Yuan T.-Q., Argyropoulos D.S., Sun R.-C., Structure-property relationships for technical lignins for the production of ligninphenol-formaldehyde resins, Industrial Crops and Products, Vol. 108, 2017, P. 316326, ISSN 0926-6690. URL: https://doi.org/10.1016/j.indcrop.2017.07.009; Sjöström E., Chapter 4 - LIGNIN, In Wood Chemistry (Second Edition), Academic Press, San Diego, 1993, P. 71-89, ISBN 9780080925899, https://doi.org/10.1016/B978-0-08092589-9.50008-5; Gellerstedt G., Henriksson G., Chapter 9 - Lignins: Major Sources, Structure and Properties, In Monomers, Polymers and Composites from Renewable Resources, edited by Mohamed Naceur Belgacem and Alessandro Gandini, Elsevier, Amsterdam, 2008, P. 201-224, ISBN 9780080453163. URL: https://doi.org/10.1016/B978-0-08-045316-3.00009-0. 
полученные в ходе расщепления эфира, реагируют с ионами бисульфита $\left(\mathrm{HSO}_{3}{ }^{-}\right)$, чтобы дать сульфонаты.

$$
\begin{gathered}
\mathrm{ROR}^{\prime}+\mathrm{H}^{+} \rightarrow \mathrm{R}^{+}+\mathrm{R}^{\prime} \mathrm{OH} \\
\mathrm{R}^{+}+\mathrm{HSO}_{3}^{-} \rightarrow \mathrm{R}^{-} \mathrm{SO}_{3} \mathrm{H}
\end{gathered}
$$

Первичным местом для расщепления эфира является атом углерода боковой цепи, присоединенный к ароматическому кольцу. Приведенные ниже схемы структуры являются схематичными, так как лигнин и его производные являются сложными смесями полимеров. Группы $\mathrm{R}^{1}$ и $\mathrm{R}^{2}$ могут быть самыми разнообразными группами, встречающимися в структуре различных форм природного лигнина. Сульфирование происходит в боковых цепях, а не на ароматическом кольце ${ }^{33}$ :

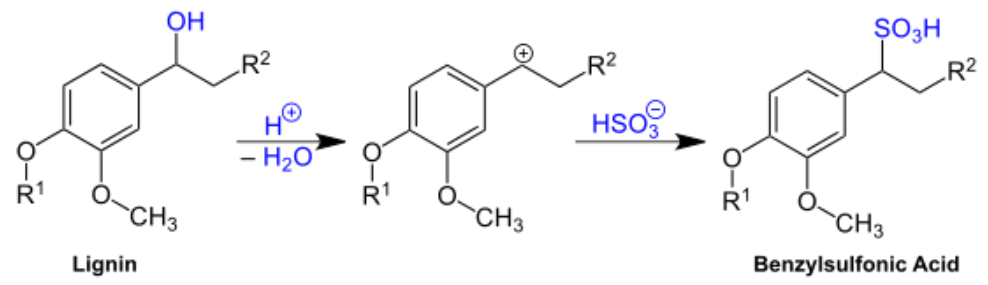

Лигносульфонаты имеют широкие диапазоны молекулярной массы и широкое молекулярное массовое распределение. Оно изменяется в диапазоне от 1000-140 000 Дальтон. Для лигносульфонатов хвойных пород средняя молекулярная масса молекул лигносульфонатов имеет более низкие значения, и более высокие для лиственных пород ${ }^{34}$. Такое строение молекул определяет свойства технических лигносульфонатов и характеризует их как анионактивные ПАВ. Технические

33 Sjöström E., Chapter 4 - LIGNIN, In Wood Chemistry (Second Edition), Academic Press, San Diego, 1993, P. 71-89, ISBN 9780080925899, https://doi.org/10.1016/B978-0-08-092589-9.50008-5.

${ }^{34}$ Gargulak, J. D., Lebo, S. E. and McNally, T. J. (2015). Lignin. In Kirk-Othmer Encyclopedia of Chemical Technology, John Wiley \& Sons, Inc (Ed.). doi:10.1002/0471238961.12090714120914.a01.pub3; Sjöström E., Chapter 4 LIGNIN, In Wood Chemistry (Second Edition), Academic Press, San Diego, 1993, P. 71-89, ISBN 9780080925899. URL: https://doi.org/10.1016/B978-0-08-0925899.50008-5. 
лигносульфонатов проявляют связующие, клеящие, диспергирующие свойства, не токсичны, хорошо растворимы в воде ${ }^{35}$.

Как известно, электролиты оказывают сильное влияние на растворимость неэлектролитов и, соответственно, неэлектролиты оказывают влияние на растворимость электролитов. Эти явления были описаны в многочисленных работах ${ }^{36}$. Они получили названия высаливания и всаливания. Таким образом, вводя в состав растворов электролиты, можно за счет этих эффектов уменьшить растворимость электролитов в воде и добиться ускорения их кристаллизации. Исследования влияния $\mathrm{NaCl}$ на растворимость различных веществ в воде показали, что высаливающее действие зависит и от природы неэлектролита. Различие в действии солей на неэлектролиты связано с ориентацией молекул воды в гидратной сфере иона. Когда катион образует гидратный комплекс, молекулы воды ориентируются таким образом, что протоны находятся снаружи комплексного иона. За счет водородных связей к этим протонам притягиваются молекулы неэлектролита ${ }^{37}$. Так, например, дипольный момент молекулы глицерина составляет величину $\mu=2,56$ Дб. Соответственно, для хлорида натрия высаливание составляет порядка $3,5 \%$. Поскольку глицерин является распространенным, не дорогим и не токсичным продуктом, то он был выбран в качестве высаливающей добавки.

Кроме того, введение добавок лигносульфоната и глицерина в композицию позволяет усилить эффект А.Ф. Иоффе, который был описан выше. Вода в исходной композиции растворяет дефекты на поверхности кристаллов соли и залечивает микроскопические трещины, являющиеся концентраторами напряжений в материале. В свою очередь, пленка из лигносульфоната, образующаяся на поверхности кристаллов соли, защищает их от появления новых

35 Расширение использования технических лигносульфонатов в народном хозяйстве: Материалы всесоюзного научно-технического семинара. Москва, 1967. С. 62; Чудаков М.А. Промышленное использование лигнина. Москва : Лесная промышленность, 1972. С. 62.

${ }^{36}$ Sergeeva V.F., Salting-out and salting-in of non-electrolytes, Russ. Chem. Rev., 1965, vol. 34, 4, p. 309-318. URL: https://doi.org/10.1070/ RC1965v034n04ABEH001446.

37 Sergeeva V.F., Salting-out and salting-in of non-electrolytes, Russ. Chem. Rev., 1965, vol. 34, 4, p. 309-318. URL: https://doi.org/10.1070/ RC1965v034n04ABEH001446. 
трещин и дефектов. Наличие глицерина в составе сформированной пленки также дополнительно усиливает ее защитный эффект.

Хлорид натрия перед использованием измельчали и использовали фракцию размером менее 0,5 мм. Технические лигносульфонаты использовали в виде натриевых солей в порошкообразном состоянии. Их растворяли в необходимом количестве дистиллированной воды и в приготовленный раствор добавляли расчетное количество глицерина квалификации «чистый». Затем готовили композицию из полученного раствора и твердого хлорида натрия. Приготовление исходных смесей заданного состава осуществляют в смесителях периодического действия с z-образными лопастями при $20 \pm 5^{\circ} \mathrm{C}$. После этого композиции формовали послойным уплотнением в пресс-формах размером $400 \times 300 \times 45$ мм с использованием вибрации и высушивали в печи при $105^{\circ} \mathrm{C}$ в течение 35 час. Из полученных заготовок вырезали образцы для испытаний размером $40 \times 40 \times 80$ мм. Перед испытаниями образцы подвергали сушке до постоянного веса при $130^{\circ} \mathrm{C}$. Испытания образцов полученного водоразрушаемого композитного материала проводили путем измерения прочности на сжатие на испытательной машине. Исследование свойств образцов проводили в зависимости от содержания в композиции: воды и лигносульфоната натрия. Определение характеристик проводили по трем параллельным образцам. Результаты испытаний представлены на Рисунке 6.

Как видно из рисунка 6, применение указанной композиции позволяет повысить прочность на сжатие материала формообразующих изделий до 15,0 20,0 МПа. Испытания материала проводились при температуре $20^{\circ} \mathrm{C}$. Повышение температуры проведения прочностных испытаний до $150^{\circ} \mathrm{C}$ показало, что прочность материала снижается в среднем до $80 \%$ от значений прочности при $20^{\circ} \mathrm{C}$. Из представленных данных видно, что основным фактором, определяющим прочность материала, является содержание воды в исходной композиции. Сам по себе лигносульфонат не несет функции связующего. Из рисунка 6 хорошо видно, что он является только модифицирующей добавкой. Однако их совместное присутствие с водой дает большой синергетический эффект, который выражается в наличии на представленном рисунке мощного максимума. Наличие такого максимума еще раз подтверждает существование эффекта А.Ф. Иоффе. 

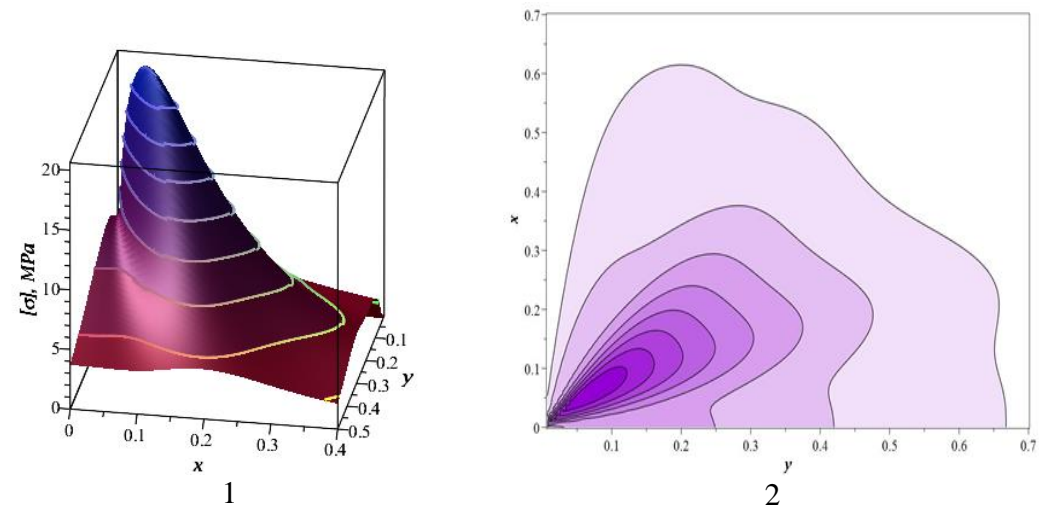

Рисунок 6. Прочность на сжатие водоразрушаемого композитного материала в зависимости от содержания в композиции: воды и лигносульфоната натрия. [б] - Разрушающее напряжение при сжатии для образцов из композитного материала, МПа; $\boldsymbol{x}$ - отношение содержания воды к содержанию $\mathrm{NaCl}$ в композиции; $y$ - отношение содержания лигносульфоната натрия к содержанию $\mathrm{NaCl}$ в композиции. 1 - Трехмерный вид; 2 - Изолинии

При изготовлении изделий из композиционных материалов методом намотки важным показателем является коэффициент линейного термического расширения (КЛТР) материала. Это связано с тем, что при нагревании формообразующего материала или оправки в процессе изготовления изделий расширение материала может привести к значительным внутренним деформациям, вплоть до их разрушения. Поэтому важной задачей являлось получение материалов с низкими значениями коэффициентов линейного термического расширения.

Определение коэффициентов линейного термического расширения проводили на установке по дилатометрическим измерениям и изучению термомеханических свойств полимеров - УИП-70М. Установка обеспечивает автоматическое измерение и регистрацию деформаций, возникающих при одноосном сжатии исследуемого образца под действием различных фиксированных нагрузок. Испытания проводили в режиме дилатометрических измерений удельное давление в диапазоне $0 \div 6$ MПа. В ряде случаев это соответствует величинам контактных давлений, имеющихся при намотке изделий из полимерных композиционных материалов на разрушаемые оправки. Результаты термомеханических исследований для различных образцов представлены на Рисунке 7. 
Приведенные результаты свидетельствуют о возможности регулирования КЛТР материала при сжимающей нагрузке путем введения в состав композиции глицерина в количестве $0,1 \div 1,2$ масс.\%. Таким образом, предлагаемая композиция обладает почти в 2 раза большей прочностью по сравнению с известными составами. Разработанная композиция также обладает меньшим коэффициентом линейного температурного расширения, что позволяет, в частности, использовать ее при изготовлении крупногабаритных изделий.

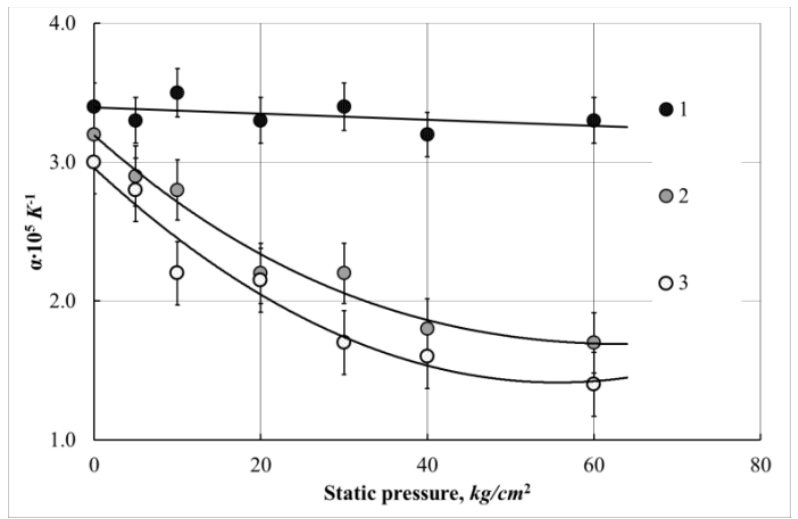

Рисунок 7. Результаты исследования термомеханических свойств полученных материалов. $\alpha$ - коэффициент линейного термического расширения. ЛСН - лигносульфонат натрия. Г - глицерин. 1 - образец состава $\mathrm{NaCl}-86 \%$, ЛСН - 6\%; Г- $0,1 \% ; \mathrm{H}_{2} \mathrm{O}-7,9 \%$. 2 - образец состава $\mathrm{NaCl}-90 \%$, ЛСН - 4\%; $\mathrm{\Gamma}-0,5 \% ; \mathrm{H}_{2} \mathrm{O}-5,5 \%$. 3 - образец состава $\mathrm{NaCl}-93 \%$, ЛСН - 1\%; Г-1,2\%; $\mathrm{H}_{2} \mathrm{O}-5,0 \%$

На основе проведенных исследований можно рекомендовать для создания водоразрушаемых конструкционных материалов композиции из хлорида натрия, лигносульфонатов, глицерина при следующем соотношении компонентов в масс. \%:

- Хлорид натрия - 86,0 $\div 93,0$;

- Технические лигносульфонаты - 1,0 $\div 6,0$

-Глицерин $-0,1 \div 1,2$

-Вода - Остальное. 


\section{4. Определение скорости растворения \\ водоразрушаемых материалов}

Важным свойством, определяющим возможность использования композиций для изготовления водоразрушаемых материалов, является скорость их растворения в воде при удалении оправки из внутренней полости готового изделия. Процесс растворения солей в воде можно представить в виде трех стадий:

- разрушение кристаллической решетки соли благодаря изменению электростатических сил при попадании соли в среду с большой диэлектрической проницаемостью;

- гидратация ионов соли;

-проникание молекул воды к поверхности растворяемого кристалла и переход гидратированных ионов вглубь раствора.

Последняя стадия наиболее продолжительна, поэтому процесс растворения сводится к диффузии растворяемого вещества из пограничной пленки в окружающую среду. Однако одной диффузии недостаточно для понимания явлений, происходящих при растворении соли. Для этого должны учитываться также гидродинамические условия, влияние силы тяжести и вязкости раствора.

В литературе имеются указания, что плавленая поваренная соль растворяется медленнее природной соли, а синтезированная поваренная соль растворяется быстрее природной каменной соли. Однако проведенные эксперименты показали, что природа соли не влияет на скорость ее растворения ${ }^{38}$. В процессе растворения соли наиболее медленной является стадия массопереноса, а скорость процесса в целом определяется скоростью именно этой стадии. Таким образом, кинетические закономерности такого процесса определяются закономерностями доставки вещества от поверхности твердой фазы из зоны растворения. Кинетика указанных процессов является диффузионной кинетикой. Она определяется, в основном, скоростью диффузии ионов соли из насыщенного раствора у поверхности растворяемого кристалла соли в объем раствора с меньшей концентрацией ${ }^{39}$.

38 Ксензенко В.И., Кононова Г.Н. Теоретические основы процессов переработки галургического сырья. Москва : Химия, 1982, 328 с.

${ }^{39}$ Фурман А.А., Шрайбман С.С. Приготовление и очистка рассола. Москва : «Химия», 1966, 232 с.; Ксензенко В.И., Кононова Г.Н. Теоретические основы процессов переработки галургического сырья. Москва : Химия, 1982, 328 с. 
С точки зрения термодинамики движущим потенциалом любого выравнивающего процесса является рост энтропии. В большинстве практических случаев движущей силой является концентрация $\mathrm{C}$, изменение которой обусловливает поддержание потоков вещества. Поток частиц вещества пропорционален при этом градиенту концентрации и описывается первым законом Фика:

$$
J=-D \frac{\partial C}{\partial x}
$$

где плотность потока вещества $J\left[\mathrm{~cm}^{-2} \mathrm{~s}^{-1}\right]$ пропорциональна коэффициенту диффузии $D\left[\mathrm{~cm}^{2} \mathrm{~s}^{-1}\right]$ и градиенту концентрации. Второй закон Фика связывает пространственное и временное изменения концентрации (уравнение диффузии):

$$
\frac{\partial C}{\partial t}=\frac{\partial}{\partial x} D \frac{\partial C}{\partial x}=D \frac{\partial^{2} C}{\partial x^{2}}
$$

Коэффициент диффузии $D$ зависит от температуры. В ряде случаев в широком интервале температур эта зависимость представляет собой уравнение Аррениуса:

$$
D=D_{0} e^{-\frac{E_{a}}{R T}}
$$

Если диффузия является стационарной, то распределение концентрации реагирующего вещества не зависит от времени, и в уравнение Фика следует положить $\frac{\partial C}{\partial t}=0$. Тогда очевидно, что

$$
\frac{\partial^{2} C}{\partial x^{2}}=0 \text { и } \frac{\partial C}{\partial x}=\text { const. }
$$

В начале и во время протекания процесса растворения концентрация растворяющегося вещества на поверхности твердой фазы $C_{\mathrm{s}}$ больше, чем объемная концентрация $C_{0}$. Если предположить, что изменение концентрации происходит в пределах некоторого слоя $\delta$, называемого диффузионным, то тогда при линейном характере этого изменения имеем

$$
\frac{\partial C}{\partial x}=\frac{C_{0}-C_{s}}{\delta}
$$


Из этого уравнения хорошо видно, что ускорить процесс можно уменьшая толщину диффузионного слоя или уменьшая концентрацию растворяемого продукта в основной массе растворителя. Для случая нестационарной линейной диффузии, когда $\frac{\partial C}{\partial t} \neq 0$, имеем рост эффективной толщины диффузионного слоя, которая увеличивается пропорционально квадратному корню из времени растворения ${ }^{40}$ :

$$
\delta=\sqrt{\pi D t}
$$

Этот факт указывает на то, что скорость растворения будет уменьшаться не только за счет роста концентрации растворенного вещества в объеме растворителя, но и за счет роста толщины диффузионного слоя.

Установлена зависимость между константой скорости растворения и величиной относительной вязкости раствора, насыщенного растворяемой солью, что подтверждает предположение о существовании у поверхности кристалла растворяемой соли межфазного слоя раствора, почти насыщенного растворяемой солью ${ }^{41}$. Вязкость этого слоя определяет скорость диффузии растворяемой соли и таким образом влияет на скорость растворения.

Особо важным фактором является перемешивание раствора. При очень интенсивном перемешивании процесс растворения перестает быть диффузионным, то есть прекращается тормозящее влияние третьей стадии. В отсутствие перемешивания (как, например, в природных условиях подземного выщелачивания) скорость растворения солевого пласта в основном будет определяться коэффициентом диффузии ионов соли. Также положительное влияние на скорость растворения соляных монолитов оказывает циркуляция растворов. Благодаря циркуляции, растворяющие рассолы будут интенсивно и турбулентно перемешиваться, соответственно солевой монолит будет растворяться значительно быстрее.

Для упрощения анализа экспериментальных данных по изучению процессов водного разрушения разработанных материалов для изготовления оправок можно отойти от детального

40 Коробов В.И., Очков В.Ф. Химическая кинетика. Введение с Mathcad/Maple/MC5. Москва : Горячая линия -Телеком, 2009, 384 c.

${ }^{41}$ Фурман А.А., Шрайбман С.С. Приготовление и очистка рассола. Москва, «Химия», 1966, 232 с. 
рассмотрения механизма процесса растворения. Его можно рассматривать как простую гетерогенную химическую реакцию, протекающую на основании закона действующих масс. При этом для ее описания можно использовать классические уравнения химической кинетики. В такой формулировке уравнение, описывающее процесс растворения, будет иметь следующий вид:

$$
W=\frac{1}{S} \frac{d C}{d t}=k(T) \cdot C^{n}
$$

где $W$ - скорость реакции растворения. В данной системе для удобства обработки экспериментальных данных скорость реакции растворения рассматривается в единицах скорости линейного перемещения растворяющейся поверхности;

$k(T)$ - константа скорости реакции растворения, зависящая от температуры процесса, геометрии частиц соли, гидродинамических условий его протекания и в некоторых случаях от концентрации соли в растворе;

$n$ - порядок реакции, с учетом простоты реакции и наличия в процессе только одного растворяемого компонента, может быть принят равным $n=1$;

$S$ - площадь поверхности раздела фаз между твердой солью и контактирующим с ней раствором.

Как уже отмечалось, скорость растворения соли возрастает с ростом температуры. Результаты изучения влияния температуры на процесс растворения представлены на рисунке 8, в виде зависимости константы скорости от температуры. Рассчитанная для этих данных энергия активации процесса растворения составляет $E_{\text {акт }}=17.2 \kappa Д ж /$ моль. 


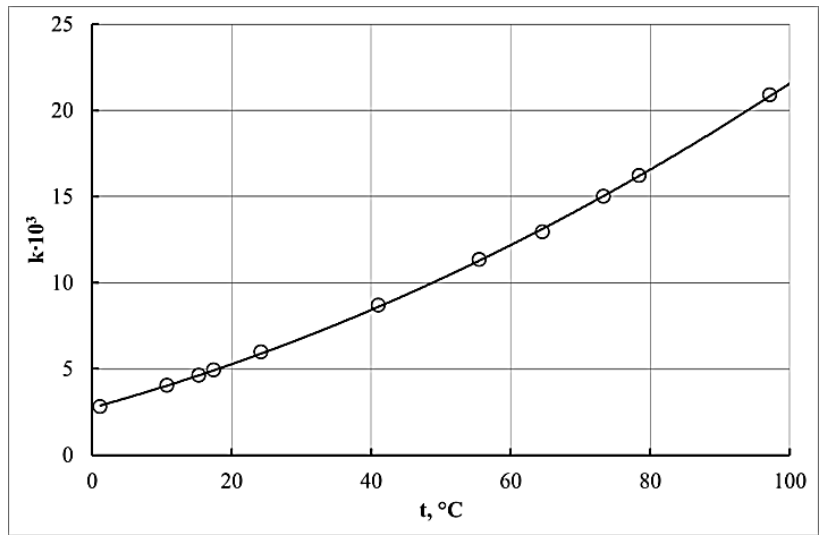

\section{Рисунок 8. Зависимость константы скорости $(k)$ растворения хлорида натрия от температуры ${ }^{42}$}

Большой опыт по изучению скорости растворения монолитных образцов соли был накоплен в результате разработки методов подземного растворения солей ${ }^{43}$. Опираясь на этот опыт, мы изучили влияние различных факторов на скорость растворения монолитных образцов хлорида натрия в условиях свободной конвекции. При этом было обнаружено существенное влияние направления силы тяжести по отношению к поверхности монолитных образцов при их растворении.

Зависимость скорости $\boldsymbol{W}$ и константы скорости $\boldsymbol{k}$ растворения соли от еe концентрации в растворе при прохождении массообменных процессов в условиях свободной конвекции приведена на рис. 9 и 10. На рисунке 9 также представлены данные по скорости растворения монолитных образцов соли, поверхность которых расположена под разными углами $\theta$ по отношению к линии горизонта.

42 Фурман А.А., Шрайбман С.С. Приготовление и очистка рассола. Москва, «Химия», 1966, 232 с.

${ }^{43} \mathrm{CM}^{42}$ 


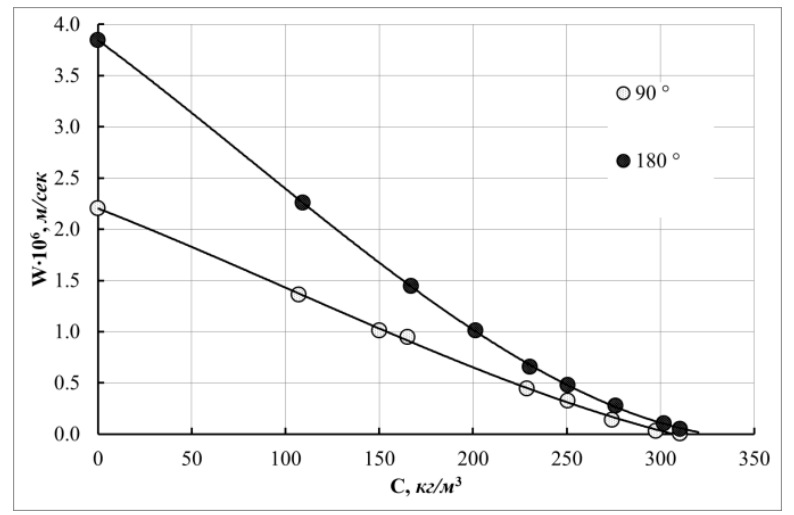

Рисунок 9. Зависимость скорости растворения соли от концентрации ее в растворе при $25^{\circ} \mathrm{C}$. Углы наклона растворяемого образца равных 90 и $180^{\circ}$. Растворение проводилось в условиях свободной конвекции. Углы наклона $\theta$ поверхности растворяемого образца составляли 90 и $180^{\circ}$. Расчеты проведены на основе данных, представленных в работе ${ }^{44}$

Нелинейный характер функции $\boldsymbol{W}(\mathrm{C})$ обусловлен существенным изменением константы $\boldsymbol{k}(\mathrm{C})$ скорости растворения $\mathrm{NaCl}$ в зависимости от концентрации соли в растворителе. Как следует из рисунка 10, этот эффект особенно заметен в области высоких концентраций соли. Эффект геометрии расположения образцов по отношению к направлению силы тяжести весьма заметен, особенно при большой концентрации раствора. Можно предположить, что этот эффект обусловлен движением более концентрированных растворов под действием силы тяжести в нижнюю часть сосуда, в котором происходит растворение образцов. Этот эффект практически приводит к дополнительной конвекции и уменьшению толщины диффузионного слоя.

${ }^{44}$ Schmid B., Boas W., Crystal Plasticity, Springer, Berlin, 1936. 


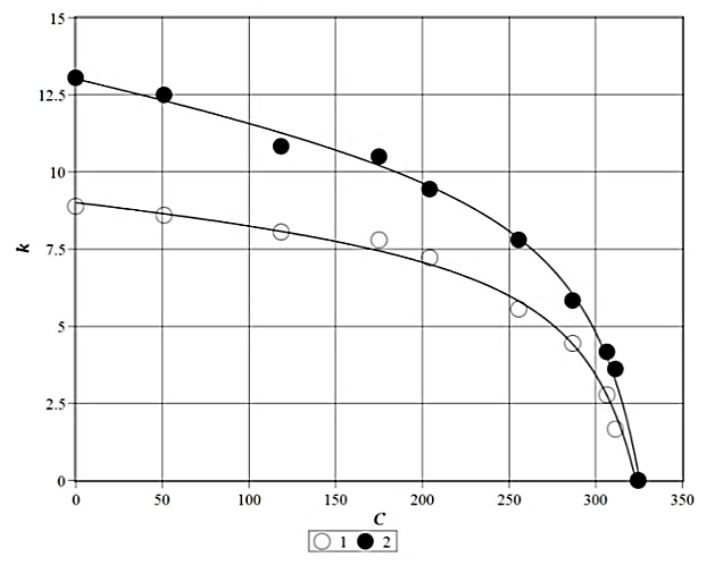

Рисунок 10. Зависимость константы скорости растворения $\mathrm{NaCl}\left(\boldsymbol{k} \cdot 10^{3}\right)$ от ее концентрации $\left(\mathrm{C}, \kappa 2 / \mathrm{m}^{3}\right)$ в водном растворе при различной температуре $\left(1-10^{\circ} \mathrm{C} ; 2-25^{\circ} \mathrm{C}\right)$. Растворение проводилось

в условиях свободной конвекции для вертикальной поверхности образца соли $\left(\theta=90^{\circ}\right)$. Расчеты были проведены на основе данных, представленных в работе ${ }^{45}$

Как было показано в работе ${ }^{46}$, при растворении соли в геологических пластах большое значение имеет угол наклона растворяющейся поверхности. На рисунке 11 показано, что с уменьшением угла наклона растворяющейся поверхности скорость выщелачивания резко снижается. Особенно этот эффект заметен при угле менее $90^{\circ}$. При подземном выщелачивании солей эксплуатация скважины прекращается, если угол наклона стенки депрессионной воронки становится менее $30 \div 40^{\circ}$. Кроме того, прекращение эксплуатации связано с отложением на растворяющихся поверхностях нерастворимых включений, предельный угол естественного откоса которых составляет также $30 \div 35^{\circ}$. Поэтому растворение соли целесообразно вести таким образом, чтобы реакционная поверхность находилась под таким углом, который значительно превышает предельный угол растворения.

${ }^{45}$ Schmid B., Boas W., Crystal Plasticity, Springer, Berlin, 1936.

46 Ксензенко В.И., Кононова Г.Н. Теоретические основы процессов переработки галургического сырья. Москва : Химия, 1982, 328 с. 


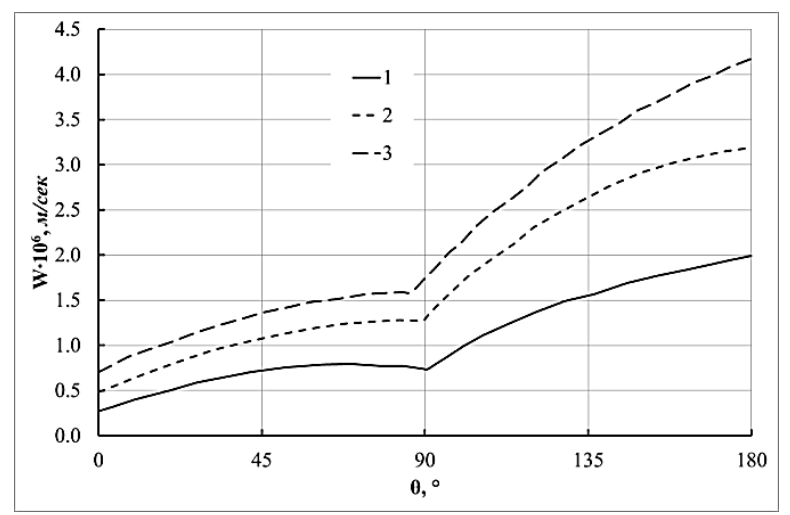

Рис. 11. Зависимость скорости растворения каменной соли в воде от угла наклона растворяющейся поверхности. Температура:

$$
1-0,5^{\circ} \mathrm{C} ; 2-15^{\circ} \mathrm{C} ; 3-25^{\circ} \mathrm{C}^{47}
$$

В случае размывания солевых оправок больших размеров, особенно в корпусах крупногабаритных ракетных двигателей, этот процесс желательно вести при вращении корпуса двигателя вокруг центральной оси. Это будет приводить к усреднению угла растворяющейся поверхности, к турбулизации течения раствора и к дополнительному его перемешиванию. Все это в совокупности будет приводить к ускорению процесса разрушения оправок.

Кроме температуры, угла наклона поверхности растворения и концентрации соли в растворе, заметное влияние на кинетику растворения соли оказывает перемешивании раствора, а именно скорость движения растворителя относительно поверхности соли. Эффект ускорения процесса растворения соли при движении растворителя обусловлен уменьшением толщины диффузионного пограничного слоя, что приводит к увеличению константы скорости растворения. Он также обусловлен отрывом пограничного слоя при движении жидкости против течения слоя или при ее турбулентном движении. Наличие пор в структуре образцов соли также способствует ускорению ее растворения, особенно за счет протекания раствора через слой соли.

47 Ксензенко В.И., Кононова Г.Н. Теоретические основы процессов переработки галургического сырья. Москва : Химия, 1982, 328 с. 
Кроме того, совершенно не обязательно добиваться полного растворения материала оправки при его вымывании. Вполне достаточно достичь частичного растворения, при котором нарушится монолитность материала оправки и произойдет ее разрушение с образованием суспензии соли в ее растворе. Эта суспензия может быть легко удалена из корпуса изделия и использована повторно, после соответствующего кондиционирования.

\section{5. Расчет плотных упаковок компонентов дисперсной фазы}

Как уже отмечалось в нашей предыдущей работе ${ }^{48}$, прочность водоразрушаемых композиционных материалов во многом определяется дисперсным составом наполнителя, используемого при их получении. В случае большой концентрации частицы дисперсного наполнителя расположены близко между собой. Создаваемые микрочастицами силовые поля пересекаются и оказывают взаимное влияние друг на друга, что существенно отражается на свойствах композита уже на макроуровне. При этом зависимость силы взаимодействия между соседними включениями от величины зазора между ними имеет значительную нелинейность. В связи с этим можно констатировать, что именно структура и топология заполнения объема материала дисперсными частицами наполнителя является одним из основных факторов в формировании деформационных и прочностных свойств высоконаполненного зернистого композита.

Как известно, прочность материалов на основе структурированных дисперсных систем зависит от пористости и диаметра исходных дисперсных частиц. Эта связь описывается эмпирическим уравнением, аппроксимирующим зависимость прочности образцов хрупких поликристаллов от комбинированного эффекта пористости и размера зерен. Она была разработана на основе экспериментальных данных, имеющихся в литературе. Полученная закономерность была проверена на данных, полученных для

${ }^{48}$ Kudryavtsev P. Composite materials for manufacture of water destroyable form-forming equipment. Journal "Scientific Israel- Technological Advantages", Vol.20, № 1, 2018, pp.40-45, ISSN: 1565-1538. 
образцов оксида тория и карбида хрома. Эта зависимость может быть описана формулой Кнудсена ${ }^{49}$ :

$$
P=K \cdot d^{-a} \cdot \exp (-b \cdot \alpha)
$$

где $P$ - прочность материала; $K$ - пересчетный коэффициент; $d$ - диаметр частиц дисперсной фазы; $a, b$ - константы; $\alpha-$ пористость сформированной структуры. Уравнения предлагаемой формы были сопоставлены на основе экспериментальных данных и позволяют в определенной степени предсказать значения прочности с точностью до $\pm 10 \%$. Вариации происходят как следствие температуры, при которой образцы были изготовлены. Этот фактор оказывает дополнительное влияние на прочность без учета того, что обусловлено результирующими изменениями пористости и размера зерна. Это явление находит свое отражение в уменьшении величины константы $\boldsymbol{b}$, происходящем с увеличением максимальной температуры изготовления образцов. Вне зависимости от имеющихся ограничений это уравнение имеет фундаментальное значение. Из этого соотношения следует однозначный вывод о том, что для получения материала с максимальным уровнем физикомеханических характеристик необходимо добиться его минимальной пористости и, соответственно, максимальной плотности упаковки частиц дисперсной фазы.

В работе ${ }^{50}$ приведен обзор основных методов исследования геометрии структур из случайно расположенных частиц круглой формы. Предложен алгоритм компьютерного синтеза пространственных систем из моно- и полифракционных плотных случайных упаковок жестких сфер с заранее заданной степенью наполнения. Проведено исследование структурных характеристик численно синтезированных случайных геометрических систем. Для двухфракционных наполнений установлены оптимальные гранулометрические составы.

49 Knudsen F.P. Dependence of Mechanical Strength of Brittle Polycrystalline Specimens on Porosity and Grain Size. Amer. J. Ceramic. Soc. 1959, V.42, No 8, P. 376-387. URL: https://doi.org/10.1111/j.1151-2916.1959.tb13596.x

50 Garishin O.C., Moshev V.V., Modelling of mechanical behaviour of damageable particulate composites, Theoretical and Applied Fracture Mechanics, Volume 31, Issue 1, 1999, Pages 61-66, ISSN 0167-8442. URL: https://doi.org/10.1016/S0167-8442(98)00067-6. 
Для регулярных плотных монодисперсных упаковок степень наполнения есть величина, строго определенная для каждого типа структуры, и может быть легко вычислена теоретически. Так, для кубической решетки ее значение равно $52.36 \%$, а для плотнейшей гексагональной упаковки составляет 74.05\%. Экспериментально установлено $^{51}$, что для случайной монодисперсной структуры из сферических элементов предельная степень наполнения составляет около $63.7 \%$. Это значение лежит примерно посредине между наполнениями, характерными для кубической и гексагональных упаковок, причем локальные флуктуации по объему структуры могут достигать до $10 \%$ от среднего значения ${ }^{52}$. Отсюда следует, что в реальных структурах довольно сложно добиться высокой плотности заполнения и такие задачи решаются только методами создания полидисперсных структур, в которых малые частицы занимают пустые пространства между крупными упакованными частицами. При этом еще более мелкие частицы занимают оставшиеся более малые полости.

Плотность упаковки дисперсного материала с непрерывным распределением частиц по размерам можно рассчитать по методике, описанной в работе ${ }^{53}$. В соответствии с этой методикой принято считать, что к плотным относятся дисперсные продукты, получаемые из совокупности фракций наполнителей, диаметр зерен в которых уменьшается в 2 раза от фракции к фракции, а количество соответствующих фракций по весу составляет 0,7 $\div 0,9$ долей от массы предыдущей фракции. Это число называется коэффициентом совпадения и показывает в каком соотношении находится данная фракция по отношению к предыдущей фракции с большим размером частиц.

Гранулометрический состав, необходимый для создания плотной упаковки дисперсного материала, определяется по уравнению (15)

${ }^{51}$ Scott G.D. Radial distribution of the random close packing of equal spheres. Nature. 1962. V. 194, № 9. P. 956-958; Scott G.D., Kilgour D.M. The density of random close packing of spheres. Brit. J. Appl. Phys. Ser. 2. 1969. V. 2. P. 863-866.

52 Займан Дж. Модели беспорядка. Теоретическая физика однородно неупорядоченных систем. Москва : Мир, 1982. 592 с.

53 Рыбьев И.А. Асфальтовые бетоны. Москва, 1969. С.300. 


$$
a_{1}+a_{1} K+a_{1} K^{2}+a_{1} K^{3}+\cdots+a_{1} K^{n-1}=100 \%,
$$

где $a_{1}-$ весовое количество первой фракции; $K-$ коэффициент сбега; $n$ - количество фракций. Таким образом, весовое количество 1-й фракции может быть рассчитано по формуле (16), а весовое количество каждой из последующих фракций, соответственно по формуле (17):

$$
\begin{gathered}
a_{1}=\frac{100 \cdot(K-1)}{K^{n}-1} \\
a_{n}=a_{n-1} \cdot K
\end{gathered}
$$

В качестве примера таких расчетов в таблице 1 представлены результаты расчета плотной упаковки дисперсных фаз с различными коэффициентами совпадения. Для наглядности получаемых результатов был выбран случай, когда дисперсный материал состоит из трех различных фракций.

Таблица 1

\section{Результаты расчета плотной упаковки \\ состава полидисперсного материала}

\begin{tabular}{|c|c|c|c|}
\hline \multirow{2}{*}{ Фракции, $\boldsymbol{м м}$} & \multicolumn{3}{|c|}{ Содержание фракции, вес. \% } \\
\cline { 2 - 4 } & $\mathbf{K = 0 , 7}$ & $\mathbf{K = 0 , 8}$ & $\mathbf{K}=\mathbf{0 , 9}$ \\
\hline $0,315 \div 0,2$ & 45,66 & 40,98 & 22.37 \\
\hline $0,2 \div 0,1$ & 31,96 & 32,78 & 26,23 \\
\hline меньше 0,1 & 22,37 & 26,23 & 29,89 \\
\hline
\end{tabular}

В качестве оптимального гранулометрического состава были выбраны фракции с коэффициентом совпадения 0,7, так как в этом случае потребуется меньшее количество фракции со средним диаметром частиц $\mathrm{d}_{\mathrm{cp}}<10^{-4}$ м. Выход такой фракции при размоле и фракционировании обычно очень мал и его изготовление требует дополнительного времени и энергозатрат на размол исходного материала.

В случайных упаковках нескольких фракций дисперсных материалов наполнение является функцией от различий в размерах частиц, их формы и соотношения объемных долей фракций. 
$\mathrm{B} \mathrm{paботах}^{54}$ предложен феноменологический метод расчета пористости для двух и более фракционных насыпных смесей, основанный на данных, полученных из обширных экспериментальных исследований. По их методике относительная ошибка в оценке пористости для смесей, состоящих из двух фракций, лежала в диапазоне от -10 до $+20 \%$, а для систем из трех и четырех фракций разброс составлял от -15 до $+25 \%$ по сравнению с опытными данными, то есть происходило некоторое систематическое завышение расчетных значений. В работе ${ }^{55}$ этот подход обобщен на случай стохастических структур с непрерывным распределением частиц по размерам.

Предложенный метод был нами доработан для исследуемой системы. С учетом внесенных корректировок и в связи с универсальностью применения предложенной методики расчета для других дискретных продуктов, считаем целесообразным привести его в более полном виде.

Введем некоторые обозначения:

$\alpha_{i}$ - доля- $i$-й фракции в продукте; $W_{i}$ - масса $i$-й фракции, 2 ; $M_{i}$ - масса навески продукта при рассеве, $2 ; d_{\text {ср }}^{i}$ - средний диаметр $i$ й фракции, $м м ; d_{1}^{i}, d_{2}^{i}-$ меньший и больший диаметры фракции, мм; $D_{\text {пр }}$ - приведенный диаметр продуктов (пр.м., пр.к. - мелкого и крупного соответственно), $м$; $l l$ - коэффициент пористости, доли ед.; $\rho_{\text {нас }}-$ насыпная плотность продукта, г/ $\mathrm{cm}^{3} ; \rho_{\text {уд }}-$ удельная плотность продукта, $2 / \mathrm{cm}^{3} ; \Psi, \mathrm{K}$ - безразмерные коэффициенты; $\mathrm{X}_{\mathrm{k}}$, $\mathrm{X}_{\mathrm{m}}$ - объемные доли продуктов.

Последовательность расчетов заключается в следующих шагах. Определяем:

-долю каждой фракции в смеси твердых дисперсных фаз

$$
\alpha_{i}=\frac{W_{i}}{M_{i}}
$$

- средний диаметр фракций компонентов смеси

54 Więckowski A., Strek F. Porowatosc mieszanin cial sypkich. Mieszaniny dwuskładnikowe. Chemia stosowana. 1966. № IB. P. 95-127; Więckowski A., Strek P. Porowate rial sypkich. Mieszaniny wieloskładnikowe. Chemia stosowana. 1966. № 4b. p. 431-447

55 Иванов В.А., Мошев В.В. Плотность упаковки сыпучих сред. Структурная механика неоднородных сред. Свердловск, 1982. С. 19-27. 


$$
d_{\mathrm{cp}}^{i}=\frac{d_{1}^{i}+d_{2}^{i}}{2}
$$

- приведенный, средневзвешенный диаметр компонентов смеси

$$
D_{\text {пр }}=\sum_{i=1}^{n} d_{\mathrm{cp}}^{i} \cdot \alpha_{i}
$$

- коэффициенты пористости исходных продуктов

$$
l=\left(1-\frac{\rho_{\mathrm{Hac}}}{\rho_{\mathrm{H}}}\right)
$$

- отношение приведенных диаметров компонентов смеси

$$
\Psi=\frac{D_{\text {пр.м }}}{D_{\text {пр.к }}} .
$$

Введем коэффициент $K_{3}$, являющийся функцией коэффициента отношения приведенных диаметров компонентов смеси:

$$
K_{3}=\frac{(1-\Psi)^{2}}{\Psi \cdot(1+5 \cdot \Psi)+(1-\Psi)^{2}}
$$

На основании литературных данных ${ }^{56}$ оптимальный состав смеси, состоящей из двух компонентов и коэффициент ее пористости, можно рассчитать по уравнениям (24), (25) и (26):

$$
\begin{gathered}
l=X_{k} \cdot l_{k}+X_{m}\left[K_{2}\left(1+l_{m}\right)-1\right] ; \\
l=X_{k} \cdot l_{k} \cdot K_{1}+X_{m} \cdot l_{m} ; \\
l=X_{k} \cdot l_{k}+X_{m} \cdot l_{m}-K_{3} \frac{l_{m}\left(1+l_{m}\right)}{1+l_{k}+l_{m}}
\end{gathered}
$$

56 Więckowski A., Strek F. Porowatosc mieszanin cial sypkich. Mieszaniny dwuskładnikowe. Chemia stosowana. 1966.№ IB. P. 95-127; 52. Więckowski A., Strek P. Porowate rial sypkich. Mieszaniny wieloskładnikowe. Chemia stosowana. 1966. №4b. p. 431-447. 
Для сложной смеси, состоящей как минимум из смеси двух фракций, возможны два варианта решения в зависимости от соотношения коэффициентов продуктов. При условии, если коэффициент пористости крупного продукта больше, чем мелкого, то оптимальный состав находится из равенств (25) и (26).

Исходя из приведенных выше выражений, рассчитываем коэффициент $K_{1}$ :

$$
K_{1}=\frac{\Psi \cdot(1+2 \cdot \Psi)}{\Psi(1+2 \cdot \Psi)+(1-\Psi)^{2}}
$$

Вычисляем объемные доли продуктов в смеси оптимального состава:

$$
\begin{gathered}
X_{k}^{*}=\frac{K_{3}\left(l_{m}+1\right)}{\left(1-K_{1}\right)\left(1+l_{m}+l_{k}\right)} \\
X_{m}=1-X_{k}^{*}
\end{gathered}
$$

Подставив оптимальные значения объемных долей в уравнения (25) или (26), вычисляем минимальный коэффициент пористости:

$$
l^{*}=l_{m}-\frac{K_{3}\left(l_{m}+1\right)\left(l_{m}-K_{1} \cdot l_{k}\right)}{\left(1-K_{1}\right)\left(1+l_{m}+l_{k}\right)}
$$

Если коэффициент пористости крупного продукта меньше, чем мелкого, то оптимальный состав находим из уравнений (24) и (26).

Отсюда рассчитываем коэффициент $\mathrm{K}_{2}$ :

$$
K_{2}=\frac{\Psi^{2}(3+\Psi)}{\Psi^{2}(3+\Psi)+(1-\Psi)^{3}}
$$

Опираясь на рассчитанные коэффициенты, вычислим объемные доли фракций в смеси оптимального состава:

$$
\begin{gathered}
X_{m}^{*}=\frac{K_{3} \cdot l_{k}}{\left(1-K_{2}\right)\left(1+l_{m}+l_{k}\right)} \\
X_{k}^{*}=1-X_{m}
\end{gathered}
$$


Подставив полученные оптимальные значения объемных долей в уравнения (24) или (26), вычислим минимальный коэффициент пористости:

$$
l^{*}=l_{k}-K_{3} \frac{l_{k}\left(l_{m}-1\right)}{\left(1+l_{m}+l_{k}\right)}\left[1+\frac{l_{m}+l_{k}}{\left(l_{k}+1\right)\left(1-K_{2}\right)}\right]
$$

Отсюда определим плотность упаковки полученной смеси:

$$
\varphi=\frac{100}{l^{*}+1}
$$

При работе с сыпучими продуктами удобнее пользоваться не объемными, а массовыми долями компонентов. Для этого необходимо учитывать плотность используемых продуктов. Массовую долю компонентов вычисляем по формуле (36):

$$
X_{\mathrm{Bec}}=X^{*} \cdot \rho
$$

Вычисляем сумму массовых долей компонентов и содержание компонентов в смеси при выражении каждой доли в процентах:

$$
X=X_{\text {вес }} \cdot \frac{100}{\sum X_{\text {вес }}}
$$

Разработанная методика была реализована в виде программы расчета плотной упаковки. Исходные данные для расчета плотной упаковки дисперсных продуктов приведены в таблице 2.

Результаты расчета необходимого соотношения двух полидисперсных продуктов приведены в таблице 3 .

Таблица 2

Исходные данные для расчета плотной упаковки дисперсных продуктов

\begin{tabular}{|c|c|c|c|c|c|c|}
\hline $\begin{array}{c}\text { № } \\
\text { композиции }\end{array}$ & $\begin{array}{c}\text { № } \\
\text { продукта }\end{array}$ & $\begin{array}{c}\text { Состав твердой } \\
\text { среды }\end{array}$ & $\begin{array}{c}\mathbf{d}_{\text {ср }}, \\
\boldsymbol{M м}\end{array}$ & $\begin{array}{c}\boldsymbol{\rho}_{\mathbf{y} д}, \\
\boldsymbol{\kappa} 2 / \boldsymbol{M}^{\mathbf{3}}\end{array}$ & $\begin{array}{c}\boldsymbol{\rho}_{\text {нас, }} \\
\boldsymbol{\kappa} 2 / \boldsymbol{M}^{\mathbf{3}}\end{array}$ & $\begin{array}{c}\text { Пористость, } \\
\mathbf{\%}\end{array}$ \\
\hline \multirow{3}{*}{ I } & 1 & $\begin{array}{c}\text { Хлорид натрия } \\
\text { крупнозернистый }\end{array}$ & 0,81 & 2165 & 1237 & 57,1 \\
\cline { 2 - 7 } & 2 & $\begin{array}{c}\text { Хлорид калия } \\
\text { мелкозернистый }\end{array}$ & 0,15 & 1980 & 1218 & 61,5 \\
\hline \multirow{2}{*}{ II } & 3 & Песок кварцевый & 0,20 & 2600 & 1602 & 61,6 \\
\cline { 2 - 7 } & 4 & $\begin{array}{c}\text { Кварц } \\
\text { пылевидный }\end{array}$ & 0,045 & 2600 & 1418 & 54,5 \\
\hline
\end{tabular}


Таблица 3

Результаты расчета упаковки двух полидисперсных продуктов

\begin{tabular}{|c|c|c|c|}
\hline $\begin{array}{c}\text { № } \\
\text { композиции }\end{array}$ & Продукт & $\begin{array}{c}\text { Весовая доля } \\
\text { (Х), мас.\% }\end{array}$ & 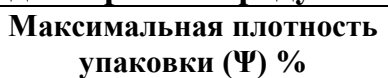 \\
\hline \multirow[t]{2}{*}{ 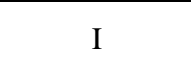 } & $\mathrm{NaCl}$ & 84.5 & \multirow{2}{*}{83,9} \\
\hline & $\mathrm{KCl}$ & 15,5 & \\
\hline \multirow[b]{2}{*}{ II } & песок & 84,4 & \multirow[b]{2}{*}{83,2} \\
\hline & $\begin{array}{l}\text { Кварцевая } \\
\text { пыль }\end{array}$ & 15,6 & \\
\hline
\end{tabular}

Составы смесей твердых фаз дисперсных продуктов, указанные в таблице 3, использовались в композициях для получения водоразрушаемых материалов.

\section{6. Результаты испытаний}

\section{полученных композиционных материалов}

При изготовлении изделий из полимерных композиционных материалов методом намотки на оправку отверждение получаемых материалов осуществляется при повышенной температуре. В связи с этим важным показателем является термическая стойкость материалов, используемых для изготовления оправок. В созданных нами композициях лимитирующим термостойкость компонентом являются технические лигносульфонаты, которые используются в качестве добавок со связующими и суперпластифицирующими свойствами. С целью установления предела их термической стойкости были проведены термогравиметрические исследования использованных в экспериментах технических лигносульфонатов. Эти исследования проводились на дериватографе Q-1500 D. Полученные результаты представлены на рисунке 12.

Проведенные исследования показали, что в интервале температур от 80 до $160^{\circ} \mathrm{C}$ происходит удаление структурированной физически связанной влаги. Энергия активации этого процесса, вычисленная методом наименьших квадратов из термографических

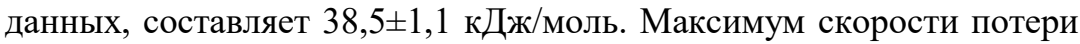
веса образца в этом процессе составляет $115 \pm 5^{\circ} \mathrm{C}$.

Повышение температуры до $200^{\circ} \mathrm{C}$ практически не вызывает процесса деструкции использованных технических лигносульфонатов. Начало процесса их деструкции наблюдается по достижении температур $215 \div 220^{\circ} \mathrm{C}$. Энергия активации этого процесса, вычисленная методом наименьших квадратов из 


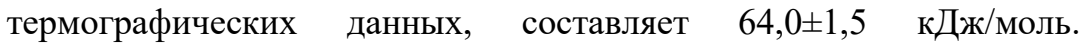
Максимум скорости потери веса образца в результате его термической деструкции составляет $285 \pm 5^{\circ} \mathrm{C}$.

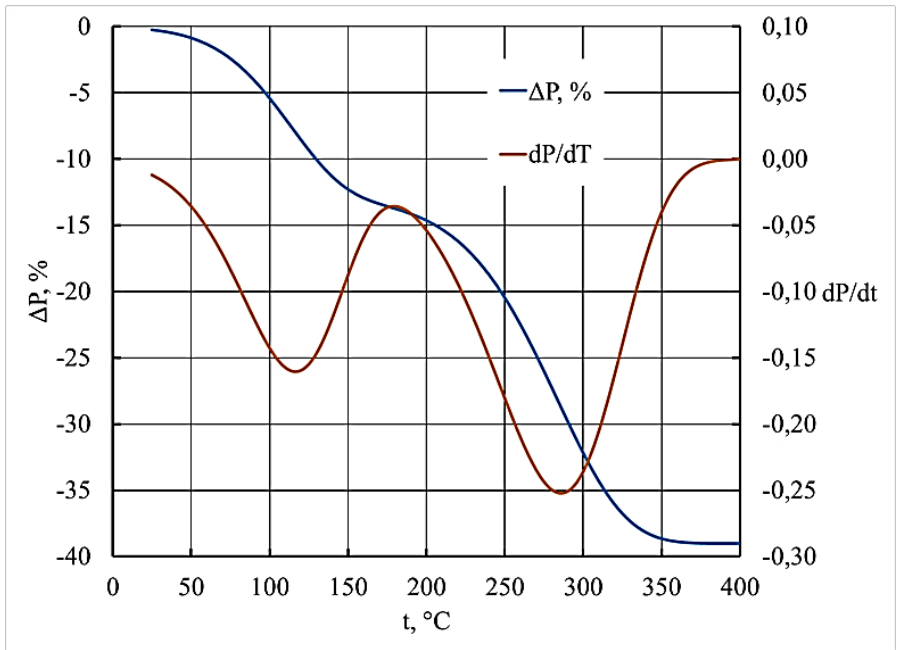

\section{Рисунок 12. Результаты термогравиметрических исследований технических лигносульфонатов}

Приведенные выше результаты позволяют рассматривать технические лигносульфонаты в качестве перспективных добавок со связующими и суперпластифицирующими свойствами для материалов водоразрушаемых формообразующих элементов повышенной теплостойкости, способных работать в условиях термического отверждения полимерных композиционных материалов.

В качестве связующего и суперпластификаторов применялись водные растворы лигносульфонатов с упрочняющими добавками ${ }^{57}$. Результаты измерения физико-механических характеристик и плотности полученных образцов разрабатываемых материалов представлены в таблице 4 .

${ }^{57}$ Kudryavtsev P. Composite materials for manufacture of water destroyable form-forming equipment. Journal "Scientific Israel- Technological Advantages" Vol. 20, № 1, 2018, pp. 40-45, ISSN: 1565-1538. 
Таблица 4

Физико-механические характеристики образцов

полученных материалов

\begin{tabular}{|c|c|c|c|}
\hline \multirow{2}{*}{$\begin{array}{c}\text { № } \\
\text { композиции }\end{array}$} & \multicolumn{2}{|c|}{ Разрушающее напряжение при сжатии, МПа } & \multirow{2}{*}{$\begin{array}{r}\rho_{\mathrm{k}}, \\
\kappa 2 / \mathbf{M}^{3} \\
\end{array}$} \\
\hline & $\sigma_{\mathrm{c} \pi}, 20^{\circ} \mathrm{C}$ & $\sigma_{\mathrm{c} \boldsymbol{N}}, 150^{\circ} \mathrm{C}$ & \\
\hline I & 14.0 & 9.0 & 1700 \\
\hline II & 43.0 & 27.0 & 2000 \\
\hline
\end{tabular}

Примечание: состав композиции в соответствии с табл. 3

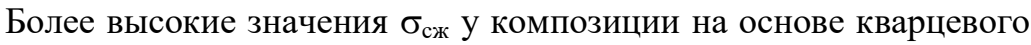
песка объясняются тем, что используемые дисперсные продукты имели меньшую крупность. Поэтому увеличивалось количество контактов на единицу сечения, что в конечном счете приводило к увеличению прочности материала.

\section{ВЫВОДЫ}

В настоящей работе проведен анализ требований, предъявляемых к физико-химическим и механическим свойствам материалов, используемых для изготовления водоразрушаемых формообразующих изделий. Изучены свойства водоразрушаемых композиционных материалов на основе жидкого стекла. На основе анализа физико-химических и механических свойств различных химических соединений произведен выбор основы для изготовления формообразующих изделий на основе водоразрушаемых материалов. При разработке водоразрушаемых конструкционных материалов нами был использован эффект, открытый А.Ф. Иоффе.

Разработаны водоразрушаемые композиционные материалы на основе галогенидов щелочных металлов для изготовления формообразующих изделий и оправок для намотки изделий типа «кокон». Композиция также содержит технические лигносульфонаты и глицерин при следующем соотношении

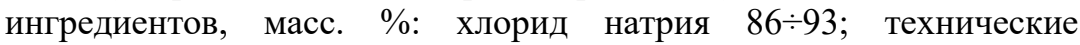
лигносульфонаты $1 \div 6$; глицерин $0,1 \div 1,2$; вода остальное.

Важным свойством, определяющим возможность использования композиций для изготовления водоразрушаемых материалов, является скорость их растворения в воде при удалении оправки из внутренней полости готового изделия. Проведены исследования по определению скорости растворения водоразрушаемых материалов в воде и предложены пути ускорения этого процесса. Исследовано 
влияние различных факторов на процесс растворения и обнаружено влияние геометрии поверхности разрушаемого материала на скорость его разрушения под действием воды.

Использование в качестве суперпластификатора лигносульфоната натрия и введение в состав смеси глицерина при указанном соотношении компонентов позволяет повысить прочность материала при одновременном снижении коэффициента температурного расширения (КЛТР).

Использование указанной композиции позволяет повысить прочность формообразующих изделий, что ведет к снижению брака отливок, вызванного преждевременным разрушением литейных стержней, и повысить удельное давление литья и тем самым расширить номенклатуру изготавливаемых изделий и ассортимент перерабатываемых, материалов. Использование композиции для изготовления водорастворимых оправок, применяемых при намотке изделий из полимерных композиционных материалов, позволит повысить прочностные характеристики материала изделий. Это достигается за счет повышения натяжения армирующих нитей и соответственно уровня контактных давлений при намотке изделий, что дает возможность уменьшить их вес при заданном уровне прочностных показателей, снизить расход дорогостоящих материалов.

На основе изложенных в настоящей работе общих принципов сформированы подходы к созданию водоразрушаемых композиций и получению на их основе водоразрушаемых материалов с высокими физико-механическими характеристиками.

Решение этой задачи связано с разработкой научных основ получения материалов для изготовления водоразрушаемых формообразующих элементов с заданными свойствами и поиском методов целенаправленного регулирования их свойств. Предложен перспективный метод получения материалов для изготовления водоразрушаемых формообразующих элементов путем структурообразования исходной дисперсной системы в результате выделения новой фазы из растворов. Показано, что в исследованных системах можно добиться значительного изменения их свойств за счет варьирования фракционного состава наполнителя, размеров и формы включений. Структура таких материалов определяющим образом оказывает влияние на их прочностные свойства. При проведении экспериментов по получению водоразрушаемых материалов в работе использовались 
компоненты дисперсной фазы на основе хлоридов натрия, калия и диоксида кремния различного гранулометрического состава. Во всех случаях использовались водорастворимые органоминеральные добавки в виде технических лигносульфонатов. Добавки лигносульфонатов выполняют в разработанных композициях несколько функций. Они одновременно являются суперпластификаторами и связующими. Полученные результаты показали, что технические лигносульфонаты можно использовать в качестве перспективных добавок, которые обладают связующими и суперпластифицирующими свойствами для материалов водоразрушаемых формообразующих элементов повышенной теплостойкости, способных работать в условиях термического отверждения полимерных композиционных материалов.

\section{АННОТАЦИЯ}

Настоящая работа относится к области машиностроения, а именно к изготовлению водоразрушаемых формообразующих изделий, например, литейных стержней, применяемых при литье металлов и пластмасс, а также изделий типа «кокон» и корпусов ракетных двигателей на твердом топливе. Кроме того, они могут быть использованы для изготовления водорастворимых оправок, применяемых при изготовлении изделий из полимерных композиционных материалов методом намотки или выкладки с использованием связующих, требующих повышенных температур отверждения и в условиях механических напряжений. Проведен анализ возможного использования различных водоразрушаемых материалов для создания подобных изделий. Проанализированы свойства водоразрушаемых композиционных материалов на основе жидкого стекла и возможности их использования для изготовления оправок. На основе проведенного анализа сделан выбор основы для изготовления основы для изготовления оправок на основе водоразрушаемых материалов. Проведен анализ физикомеханических свойств галогенидов щелочных металлов и произведен обоснованный выбор веществ основы, подходящих для изготовления водоразрушаемых композиционных материалов. Предложена рецептура и технология изготовления изделий из водоразрушаемых материалов. Проведен анализ процессов при разрушении этих материалов после их использования. 


\section{ЛИТЕРАТУРА}

1. Лавров Л.Н., Думин О.С., Соколовский М.И. и др. Конструкции ракетных двигателей на твердом топливе / Под общ. ред. чл. корр. РАН, д.т.н., проф. Л.Н. Лаврова. Москва : Машиностроение, 1993. 215 с.

2. Соколовский М.И. Развитие конструктивно-компоновочных схем крупногабаритных ракетных двигателей твердого топлива. Известия Российской Академии наук. Энергетика. № 2, 2003, с. 97.

3. Фахрутдинов И.Х., Котельников А.В. Конструкция и проектирование ракетных двигателей твердого топлива. Москва : Машиностроение, 1987.

4. Суходоева А.А. Численный анализ напряженно-деформированного состояния и оценка прочности оправок для намотки композиционных оболочек. Пермь : ПГТУ, 2000.

5. Бойко В.В. Синтез поливинилового спирта в водноспиртовых средах : дис. канд. хим. наук. 02.00.06 : Москва, 2004, $112 \mathrm{c}$.

6. Kudryavtsev P. Composite materials for manufacture of water destroyable form-forming equipment. Journal "Scientific Israel Technological Advantages”, Vol. 20, № 1, 2018, pp. 40-45. ISSN: 1565-1538.

7. Ребиндер П.А. Поверхностные явления в дисперсных системах. Физико-химическая механика : избр. тр. Москва : Химия, 1979.

8. Абрамсон А.А. и Щукин Е.Д. (ред.). Поверхностные явления и поверхностно-активные вещества. Москва : Химия, 1984.

9. Жуковский С.С., Лясс А.М. Формы и стержни из холоднотвердеющих смесей. Москва : Машиностроение, 1978. 24 с.;

10.Корнеев В.И., Юргинсон Е.Н., Кузьмин Б.А. Опыт разработки и применения связующих для легковыбиваемых формовочных смесей. Ленинград : ЛДНТП, 1986. 26 с.

11.Kudryavtsev P., Figovsky O. Advanced Nanomaterials Based on Soluble Silicates. Journal Scientific Israel - Technological Advantages. Vol. 16, № 3, 2014, p. 38-76.

12.Lebo, S. E., Gargulak, J. D. and McNally, T. J. Lignin. Kirk-Othmer Encyclopedia of Chemical Technology, John Wiley \& Son, (2001).

13.Терещенко А.Г. Гигроскопичность и слеживаемость растворимых веществ. Изд-во Томского политехнического университета, 2011.79 с.

14.Хамский Е.В. Кристаллические вещества и продукты. Методы оценки и совершенствования свойств. Москва : Химия. 1986, $224 \mathrm{c}$. 
15. Волков В.А. Разработка технологии основ неслеживемости хлорида калия : автореферат канд. дисс. Ленинград, 1986.

16. Пойлов В.3. Основы технологий некоторых кристаллических продуктов с заданными свойствами : автореферат докт. дисс. Пермь, 1998.

17. Черепанова М.В., Потапов И.С., Пойлов В.З., Попова К.В., Алиферова С.Н. Влияние условий хранения и транспортировки на физико-механические свойства гранулированного хлорида калия. Вестник ПНИПУ. Химическая технология и биотехнология. 2012. № 13.

18.Zurimendi J., Bolivar C.; Rafael A. Anti- caking composition. United States Patent № 4,772,308, Current International Class: B01J 2/30; C05C 1/02; C05C 1/00; C05G 003/00; C05C 001/02; C05C 003/00. 20.09.1988.

19. Юркина М.И. Исследование процесса устранения слеживаемости хлористого калия с помощью добавок ферроцианида и аминов : автореферат канд. дисс. Пермь, 1974.

20.Hill, J.C. Johann Glauber's discovery of sodium sulfate Sal Mirabile Glauberi. Journal of Chemical Education. 1979, Vol. 56, No 9, p. 593.

21.Гилман Дж. Механические свойства ионных кристаллов. Успехи физических наук. 1963 т. 80. Вып. 7. с. 455-503.

22. Slaughter W.S. The Linearized Theory of Elasticity, Springer, 2002, 512 p. ISBN: 978-1-4612-6608-2

23. Коробов В.И., Очков В.Ф. Химическая кинетика. Введение с Mathcad/Maple/MC5, М., Горячая линия - Телеком, 2009, 384 с.

24. Hearmon R.F.S. The Elastic Constants of Anisotropic Materials, Rev. Mod. Phys., 1946, Vol. 18, Issue 3, p. 409.

25. Morris D.F.C., The lattice energies of the alkali halides, Acta Cryst. Vol.9, 2, p.197 (1956). doi: 10.1107/S0365110X56000498

26. Harrison W.A. Solid State Theory. Dover Publications, Inc. New York, 1980. $541 \mathrm{p}$.

27.Brazhkin V.V., Grimsditch M., Guedes I., Bendeliani N.A., Dyuzheva T.I., Lityagina L.M. Elastic moduli and the mechanical properties of stishovite single crystals, Phys. Usp. Vol. 45, p. 447-448, 2002; DOI: 10.1070/PU2002v045n04ABEH001162.

28. Hearmon R.F.S. The elastic constants of anisotropic materials-II, Advances in Physics, 1956, Vol. 5, Issue 19, p. 323-382.

29. Huntington H.B. The Elastic Constants of Crystals, Solid State Physics, 1958, Vol. 7, p. 213-351.

30. Фурман А.А., Шрайбман С.С. Приготовление и очистка рассола, Москва, «Химия», 1966, 232 с. 
31.Иоффе А.Ф. Избранные труды. Том I. Механические и электрические свойства кристаллов. Изд-во «Наука», Ленингр. отд. Ленинград, 1974. стр. 1-327.

32.Joffe A., Lewitzky M. Über die Kohäsionsfestigkeit von Steinsalz, Zeitschrift fur Physik. 1929, Bd. 35. S. 442-445.

33. Фурман А.А., Бельды М.П., Соколов И.Д. Поваренная соль. Производство и применение в химической промышленности. Москва : Химия, 1989, 272 с.

34. Schmid B., Boas W., Crystal Plasticity, Springer, Berlin, 1936.

35.Бугаенко Л.Т., Рябых С.М., Бугаенко А.Л. Почти полная система средних ионных кристаллографических радиусов и ее использование для определения потенциалов ионизации. Вестник Московского университета. Серия 2: Химия. 2008. Т. 49, № 6, c. $363-385$.

36.Кудрявцев П.Г. Журавлев С.Г., Ботов В.А., Клячкин Ю.С., Лавров Л.Н., Ипанова О.П., Новгородцева М.М., Шафит Я.М., Леонов А.А., Радушев А.В., Бегишев В.П. Композиция для изготовления водорастворимых формообразующих изделий, А.С. СССР № 1696097 по заявке № $4634416 / 33$ от 9.01.89, опубл. Б.И. №45 от 07.12.91.

37.Gargulak, J. D., Lebo, S. E. and McNally, T. J. (2015). Lignin. In Kirk-Othmer Encyclopedia of Chemical Technology, John Wiley \& Sons, Inc (Ed.). doi:10.1002/0471238961.12090714120914.a01.pub3.

38.Pang B., Yang S., Fang W., Yuan T.-Q., Argyropoulos D.S., Sun R.-C., Structure-property relationships for technical lignins for the production of lignin-phenol-formaldehyde resins, Industrial Crops and Products, Vol. 108, 2017, P. 316-326, ISSN 0926-6690. URL: https://doi.org/10.1016/j.indcrop.2017.07.009.

39. Sjöström E., Chapter 4 - LIGNIN, In Wood Chemistry (Second Edition), Academic Press, San Diego, 1993, P. 71-89, ISBN 9780080925899. URL: https://doi.org/10.1016/B978-0-08-0925899.50008-5.

40. Gellerstedt G., Henriksson G., Chapter 9. Lignins: Major Sources, Structure and Properties, In Monomers, Polymers and Composites from Renewable Resources, edited by Mohamed Naceur Belgacem and Alessandro Gandini, Elsevier, Amsterdam, 2008, P. 201-224, ISBN 9780080453163. URL: https://doi.org/10.1016/B978-0-08045316-3.00009-0.

41.Расширение использования технических лигносульфонатов в народном хозяйстве: Материалы всесоюзного научно-технического семинара. Москва, 1967. С. 62.

42. Чудаков М.А. Промышленное использование лигнина. Москва : Лесная промышленность, 1972. С. 62. 
43. Sergeeva V.F., Salting-out and salting-in of non-electrolytes, Russ. Chem. Rev., 1965, vol. 34, 4, p. 309-318. URL: https://doi.org/10.1070/RC1965v034n04ABEH001446.

44. Ксензенко В. И., Кононова Г. Н. Теоретические основы процессов переработки галургического сырья. Москва : Химия, $1982.328 \mathrm{c}$.

45. Knudsen F.P. Dependence of Mechanical Strength of Brittle Polycrystalline Specimens on Porosity and Grain Size // Amer. J. Ceramic. Soc. 1959, V.42, No 8, P. 376-387. URL: https://doi.org/10.1111/j.1151-2916.1959.tb13596.x

46. Garishin O.C., Moshev V.V., Modelling of mechanical behaviour of damageable particulate composites, Theoretical and Applied Fracture Mechanics, Volume 31, Issue 1, 1999, Pages 61-66, ISSN 0167-8442. URL: https://doi.org/10.1016/S0167-8442(98)00067-6.

47. Scott G.D. Radial distribution of the random close packing of equal spheres. Nature. 1962. V. 194, № 9. P. 956-958.

48. Kilgour D.M. The density of random close packing of spheres. Brit. J. Appl. Phys. Ser. 2. 1969. V. 2. P. 863-866.

49.Займан Дж. Модели беспорядка. Теоретическая физика однородно неупорядоченных систем. Москва : Мир, 1982. 592 с.

50. Рыбьев И.А. Асфальтовые бетоны. Москва, 1969. С. 300.

51. Więckowski A., Strek F. Porowatosc mieszanin cial sypkich. Mieszaniny dwuskładnikowe. Chemia stosowana. 1966. № IB. P. 95-127.

52. Więckowski A., Strek P. Porowate rial sypkich. Mieszaniny wieloskładnikowe. Chemia stosowana. 1966. №4b. p. 431-447.

53. Иванов В.А., Мошев В.В. Плотность упаковки сыпучих сред. Структурная механика неоднородных сред. Свердловск, 1982. C. 19-27.

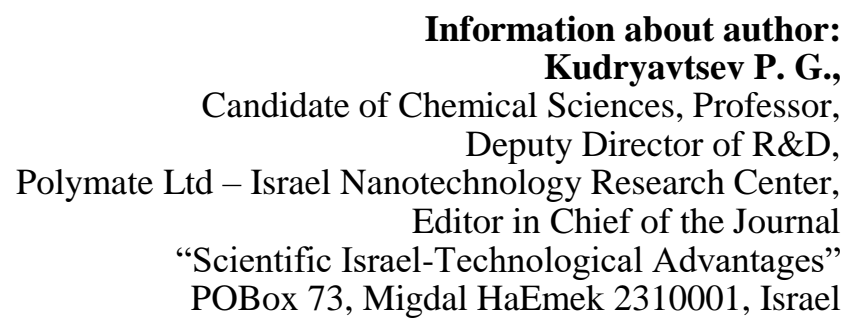

